\title{
tRNA transfers to the limelight
}

\author{
Anita K. Hopper ${ }^{1,3}$ and Eric M. Phizicky ${ }^{2}$ \\ ${ }^{1}$ Department of Biochemistry and Molecular Biology, Pennsylvania State University College of Medicine, Hershey, \\ Pennsylvania 17033, USA; ${ }^{2}$ Department of Biochemistry and Biophysics, University of Rochester School of Medicine, \\ Rochester, New York 14642, USA
}

tRNA has a central role in biology as the adaptor between mRNA and protein, in which anticodon interactions with the mRNA codon at one end of the L-shaped tRNA allow an attached amino acid at the other end of the tRNA to condense with the peptide chain on a second tRNA through the action of the ribosome. This familiar role of tRNA requires mature tRNAs to be recognized by the aminoacyl tRNA synthetase to add the amino acid to its $3^{\prime}$ end, by EF $1 \alpha$ to form a ternary complex with the aminoacylated tRNA and GTP, and by elements of the ribosome and associated components to allow binding, peptide synthesis, and translocation. Before fulfilling this role, all tRNA transcripts have to be extensively processed. Maturation of tRNAs requires five major steps: (1) removal of the 5' leader by RNase P, which almost universally requires a ribonucleoprotein complex; (2) removal of the $3^{\prime}$ trailer sequence by some combination of endonucleases and exonucleases; (3) addition of CCA in eukaryotes, many eubacteria, and some archaea; (4) splicing of introns in some tRNAs of most (if not all) eukaryotes and some archaea, by an endonuclease that excises the intron and a ligase that joins the exons; and (5) numerous modifications of tRNA at multiple residues (see Fig. 1).

Recent results have led to several fascinating new insights into tRNA biology, which are described in this review. First, there has been dramatic progress in identification of the component enzymes and corresponding genes responsible for tRNA processing. In the yeast Saccharomyces cerevisiae, 38 gene products are now known to be directly responsible for tRNA processing, most of which have been identified in the last few years (Table 1). Because the genes corresponding to 16 more modification and processing steps remain to be identified, this means that $\sim 1 \%$ of the yeast genome is directly involved in tRNA processing, not counting gene products involved in tRNA transcription and tRNA transport. Second, there has been significant progress in defining the broad outlines of specificity of several modification enzymes, and of the roles of the individual members of complexes in substrate recognition and catalysis, while

${ }^{3}$ Corresponding author.

E-MAIL ahopper@psu.edu; FAX (717) 531-7072.

Article and publication are at http://www.genesdev.org/cgi/doi/10.1101/ gad.1049103. raising new questions about the precise nature of these functions. Third, there have been new insights into the cellular role of some tRNA modification enzymes whose role had previously been obscure because of the lack of mutant phenotypes, which was at odds with their obvious evolutionary conservation. Modifications are now seen as integral components of processing that interact with and influence translation at multiple levels, that affect nuclear transport, and that influence the stability of tRNA. Fourth, new evidence underscores the interplay of tRNA processing and tRNA-processing enzymes with other major pathways in the cell such as sterol biosynthesis, the unfolded protein response, and rRNA processing. Fifth, different organisms have evolved several different methods of maturing tRNA at almost every step, some of which involve novel mechanisms. This is reflected in multiple methods of building a $3^{\prime}$ end, a novel method of building a new $5^{\prime}$ end, two different pathways for splicing tRNA, new insight into the dynamics of CCA addition, and a new look at mechanisms that control tRNA quality. Sixth, the last few years have witnessed surprises and unexpected complexities from the study of the cell biology of tRNA and its processing enzymes. These include multiple nuclear locations of both tRNA and processing enzymes, the intersection of tRNA transport and tRNA aminoacylation in the nucleus, the existence of at least two pathways for tRNA transport from the nucleus to the cytoplasm, and the emergence of a whole new pathway of mitochondrial tRNA import. In short, tRNA is charging again.

Because progress has been most rapid and complete for the yeast $S$. cerevisiae, this review concentrates on developments in yeast. However, many exciting results that have emerged from study in other organisms are also discussed.

\section{Genomic analysis and new technology have opened the field of tRNA-processing biochemistry}

The importance of bioinformatics for identifying gene products involved in processing cannot be overstated. The analyses of Koonin, Santi, and coworkers (Gustafsson et al. 1996; Koonin 1996), using iterative approaches with BLAST with known genes encoding pseudouridylases and methyltransferases, yielded several predicted Escherichia coli pseudouridylases that ultimately 


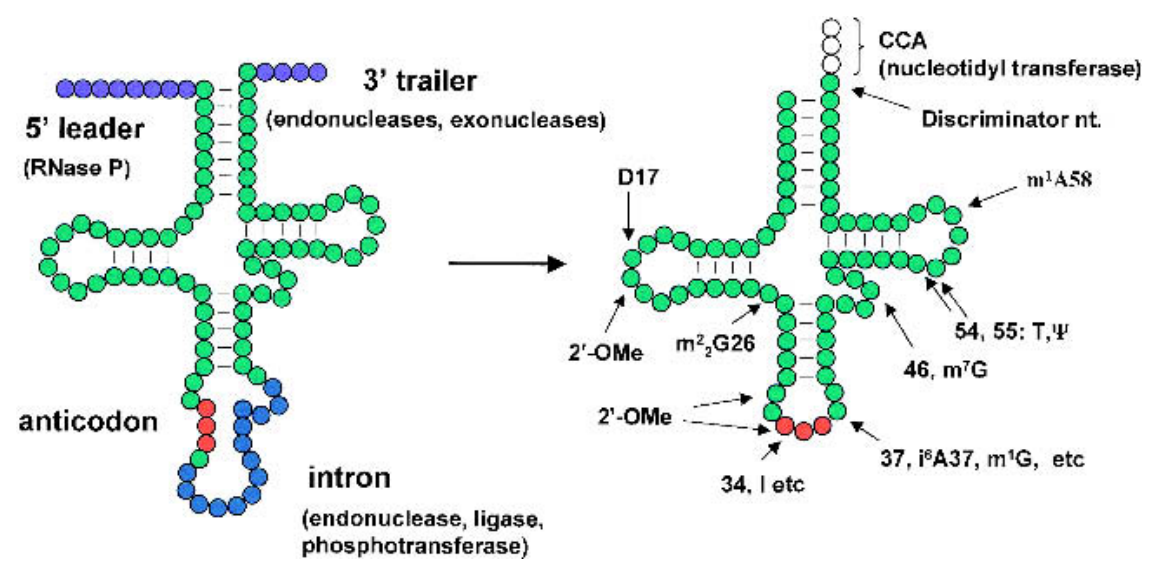

Figure 1. A schematic of a tRNA precursor and a mature tRNA. Each nucleotide is represented by a filled circle: part of the mature tRNA (green); leader and trailer sequences (purple); intron (blue); anticodon (red). The positions of several of the tRNA modifications discussed in the text are indicated on the canonical tRNA molecule shown at the right, using the usual tRNA numbering system. For reviews of the modifications, see Björk (1995) and Sprinzl et al. (1998). proved correct (Del Campo et al. 2001, and references therein), as well as several candidate yeast enzymes. These analyses, coupled with similar analysis of yeast PUS1 after its isolation in a genetic screen (Simos et al. 1996), and subsequent similar bioinformatics searches, ultimately led to the identification of genes encoding four different yeast tRNA pseudouridylases (Simos et al. 1996; Becker et al. 1997; Lecointe et al. 1998; Ansmant et al. 2001), four tRNA methyltransferases (Cavaillé et al. 1999; Motorin and Grosjean 1999; Nordlund et al. 2000; Pintard et al. 2002), and two adenosine deaminases (Gerber et al. 1998; Gerber and Keller 1999). Bioinformaticsbased identification of Trm5p, the yeast $\mathrm{m}^{1} \mathrm{G}$ methyltransferase responsible for modification at site 37 , was slightly more complicated. To accomplish this, Björk and colleagues first identified an archaeal ortholog to the E. coli $\mathrm{m}^{1} \mathrm{G}$ methyltransferase by a genetic selection, and then used a conserved region to identify the yeast gene (Björk et al. 2001).

Two very different genomic methods were used simultaneously to identify a family of dihydrouridine synthases in yeast and in E. coli. The yeast dihydrouridine synthase Dus1p was identified by a biochemical genomics approach involving parallel biochemical analysis of the yeast proteome (Xing et al. 2002). In this approach, a genomic set of 6144 yeast strains, each expressing a distinct GST-ORF fusion protein, was used to obtain 64 pools of purified yeast ORFs, each derived from 96 strains. Then pools were assayed for activity, and positive fractions were deconvoluted by preparation and analysis of subpools of the proteins (Martzen et al. 1999; Grayhack and Phizicky 2001). This biochemical genomics approach was also recently used to identify a complex of two yeast proteins that catalyze $\mathrm{m}^{7} \mathrm{G}$ formation at position 46 of tRNAs (Alexandrov et al. 2002). The $E$. coli dihydrouridine synthase family was identified by an interesting bioinformatics analysis (Bishop et al. 2002). In this study, the COG (conserved orthologous genes) database was parsed to separate those COGs that did not have representatives in an organism lacking dihydrouridine, but did have representatives in several organisms that had dihydrouridine. Of the 86 COGs that were retrieved, six were candidates because they were poorly characterized, and one of these six coclustered physically with tRNA modification activities, had some similarity to enzymes of similar biochemical activity, and proved to encode dihydrouridine synthase.

More conventional biochemical and genetic methods have also played a prominent role in identifying genes whose products are involved in tRNA processing. Brute force biochemical purification of yeast nuclear RNase $\mathrm{P}$, followed by mass spectrometry analysis of polypeptides, yielded five new polypeptide subunits of the complex, together with four previously identified polypeptide subunits and an RNA subunit (Chamberlain et al. 1998). Similar brute force purification led to the identification of TPT1, encoding the 2'-phosphotransferase that removes the splice junction phosphate in the last step of yeast tRNA splicing (Culver et al. 1997). Identification of the four subunits of the yeast splicing endonuclease proteins was accomplished by coimmunoprecipitation with an epitope-tagged construct of the one known protein subunit, followed by peptide sequencing (Trotta et al. 1997). Finally, genetic analysis led to the identification of both subunits of the $\mathrm{m}^{1} \mathrm{~A}$ methyltransferase responsible for modification of A58 of tRNAs (Anderson et al. 1998, 2000), as well as of several other genes resonsible for various modifications (Table 1).

\section{Gene discovery uncovers complexities in substrate specificity and enzyme composition}

The identification of all these genes specifying tRNAprocessing proteins has opened the door to two broad avenues of research: examination of the biochemical basis for substrate specificity and catalysis, and examination of the cellular role of the proteins. Biochemical analysis of modifications in vitro and analysis in vivo have shown that some modification enzymes, like Puslp and $\operatorname{Trm} 4 \mathrm{p}$, catalyze modifications at a variety of different positions in different tRNAs (Simos et al. 1996; Motorin et al. 1998; Motorin and Grosjean 1999), whereas others, such as Pus3p and Trm7p, are region-specific (Lecointe et al. 1998; Pintard et al. 2002), and many other modification enzymes are completely position-specific. The nature of these differences in specificity is poorly understood, although it is known that the less specific enzymes Pus $1 p$ and Trm $4 p$ recognize only local struc- 
Table 1. Genes from Saccharomyces cerevisiae whose products catalyze steps in $t R N A$ processing

\begin{tabular}{|c|c|c|c|c|c|}
\hline Yeast gene & Isolation method & Modification & Mutant phenotype & Location observed & References \\
\hline PUS1 & genetics & $\begin{array}{l}\Psi 27,28,34(35), 36 \\
(26,65,67 \text { likely); } \\
\text { U2 snRNP } 44\end{array}$ & $\begin{array}{l}\text { not essential; synthetic effects } \\
\text { with pus4, los } 1 \text {, or altered } \\
\text { minor tRNA }\end{array}$ & nucleoplasm & $\begin{array}{l}\text { Simos et al. 1996; Motorin et } \\
\text { al. 1998; Massenet et al. } \\
\text { 1999; Grosshans et al. } 2001\end{array}$ \\
\hline PUS3 (DEG1) & bioinformatics & $\Psi 38,39$ cyt., mito. & slow growth & $\begin{array}{l}\text { primarily nucleus } \\
\text { and cytosol }\end{array}$ & Lecointe et al. 1998 \\
\hline PUS4 & bioinformatics & $\Psi 55$ cyt., mito. & $\begin{array}{l}\text { not essential; synthetic effects } \\
\text { with pus1, or with altered } \\
\text { tRNA Ser }\end{array}$ & $\mathrm{ND}^{a}$ & $\begin{array}{l}\text { Becker et al. 1997; Grosshans } \\
\text { et al. 2001; Johansson and } \\
\text { Byström } 2002\end{array}$ \\
\hline PUS6 & bioinformatics & $\Psi 31$ cyt., mito. & not essential & primarily cytosol & Ansmant et al. 2001 \\
\hline PUS8 & ND & $\Psi 32$ & ND & ND & see Grosshan et al. 2001 \\
\hline TRM1 & genetics; bioassay & $\mathrm{m}_{2}^{2} \mathrm{G} 26$ & $\begin{array}{l}\text { not essential; synthetic effects } \\
\text { with altered tRNA } \\
\text { Ser }\end{array}$ & $\begin{array}{l}\text { nuclear rim; } \\
\text { mitochondria }\end{array}$ & $\begin{array}{l}\text { Ellis et al. 1986; Li et al. 1989; } \\
\text { Johansson and Byström } \\
2002\end{array}$ \\
\hline TRM2 & $\begin{array}{l}\text { genetics, } \\
\text { bioinformatics }\end{array}$ & m5 U54 cyt., mito. & $\begin{array}{l}\text { not essential; synthetic effects } \\
\text { with altered tRNA } \\
\text { Ser }\end{array}$ & ND & $\begin{array}{l}\text { Hopper et al. 1982; Nordlund } \\
\text { et al. 2000; Johansson and } \\
\text { Byström } 2002\end{array}$ \\
\hline TRM3 & bioinformatics & Gm18 & $\begin{array}{l}\text { not essential; synthetic with } \\
\text { altered tRNA }\end{array}$ & ND & $\begin{array}{l}\text { Cavaillé et al. 1999; Johansson } \\
\text { and Byström } 2002\end{array}$ \\
\hline TRM4 & bioinformatics & $\mathrm{m}^{5} \mathrm{C} 34,40,48,49$ & $\begin{array}{l}\text { not essential; paromomycin- } \\
\text { sensitive }\end{array}$ & nuclear rim & $\begin{array}{l}\text { Wu et al. 1998; Motorin and } \\
\text { Grosjean } 1999\end{array}$ \\
\hline TRM5 & bioinformatics & $\mathrm{m}^{1} \mathrm{G} 37, \mathrm{~m}^{1} \mathrm{I}, \mathrm{yW}$ & very sick & ND & Björk et al. 2001 \\
\hline TRM7 & bioinformatics & $2^{\prime}-\mathrm{O}-\mathrm{Me} 32$ and 34 & $\begin{array}{l}\text { slow growth; paromomycin- } \\
\text { sensitive; slowed translation }\end{array}$ & cytosol & Pintard et al. 2002 \\
\hline TRM8/TRM82 & $\begin{array}{l}\text { biochemical } \\
\text { genomics }\end{array}$ & $\mathrm{m}^{7} \mathrm{G} 46$ & not essential & ND & Alexandrov et al. 2002 \\
\hline MOD5 & genetics & $i^{6} \mathrm{~A} 37$ & loss of suppression & $\begin{array}{l}\text { nucleoplasm; } \\
\text { nucleolus; } \\
\text { cytoplasm; } \\
\text { mitochondria }\end{array}$ & $\begin{array}{l}\text { Laten et al. 1978; Dihanich et } \\
\text { al. 1987; Boguta et al. } 1994\end{array}$ \\
\hline GCD10, GCD14 & genetics & $\mathrm{m}^{1} \mathrm{~A} 58$ & essential & nucleus & $\begin{array}{l}\text { Anderson et al. 1998; Calvo et } \\
\text { al. 1999; Anderson et al. } \\
2000\end{array}$ \\
\hline TAD2, TAD3 & bioinformatics & A34 to I34 & essential & ND & Gerber and Keller 1999 \\
\hline DUS 1,2 & $\begin{array}{l}\text { biochemical } \\
\text { genomics; } \\
\text { bioinformatics }\end{array}$ & $\begin{array}{l}\text { D17 tRNA }{ }^{\text {Phe }} \\
\text { (Duslp, in vitro) }\end{array}$ & not essential & ND & $\begin{array}{l}\text { Bishop et al. 2002; Xing et al. } \\
2002\end{array}$ \\
\hline TAD1 & bioinformatics & $\mathrm{A} 37$ to $\mathrm{I} 37 \mathrm{tRNA}^{\mathrm{Ala}}$ & not essential & ND & Gerber et al. 1998 \\
\hline RIT1 & genetics & $\begin{array}{l}\text { 2'-O-ribosyl } \\
\text { phosphate at } 64 \text { of } \\
\text { tRNA }_{i}^{\text {Met }}\end{array}$ & $\begin{array}{l}\text { not essential; synthetic effects } \\
\text { with elF- } 2 \text { mutations }\end{array}$ & ND & $\begin{array}{l}\text { Åström and Byström 1994; } \\
\text { Åström et al. } 1999\end{array}$ \\
\hline $\begin{array}{l}\text { SEN2, SEN15, } \\
\text { SEN34, SEN54 }\end{array}$ & $\begin{array}{r}\text { genetics (SEN2); } \\
\text { copurification }\end{array}$ & splicing endonuclease & essential & ND & $\begin{array}{l}\text { Ho et al. 1990; Trotta et al. } \\
1997\end{array}$ \\
\hline TRL1 & purication & tRNA ligase & $\begin{array}{l}\text { essential; tRNA splicing and } \\
\text { HAC1 mRNA splicing }\end{array}$ & $\begin{array}{l}\text { nuclear periphery; } \\
\text { some cytosol } \\
\text { activity }\end{array}$ & $\begin{array}{l}\text { Clark and Abelson 1987; } \\
\text { Phizicky et al. } 1992\end{array}$ \\
\hline TPT1 & purification & 2'-phosphotransferase & essential & ND & $\begin{array}{l}\text { Culver et al. 1997; Spinelli et } \\
\text { al. } 1997\end{array}$ \\
\hline $\begin{array}{l}\text { POP1, POP3, } \\
\text { POP4, POP5, } \\
\text { POP6, POP7, } \\
\text { POP8, RPP1, } \\
\text { RPR2, RPR1 }\end{array}$ & purification & RNase $\mathrm{P}$ & essential & $\begin{array}{l}\text { nucleolus (some } \\
\text { nucleoplasm) }\end{array}$ & $\begin{array}{l}\text { Bertrand et al. 1998; } \\
\text { Chamberlain et al. } 1998\end{array}$ \\
\hline
\end{tabular}

${ }^{a}$ Not determined.

tural features because they can catalyze reactions on minisubstrates (Motorin et al. 1998; Motorin and Grosjean 1999|. Equally poorly understood for the majority of modifications is why only some tRNAs with the correct residue at the appropriate site are modified, whereas others are not. For several modifications, like $i^{6} \mathrm{~A}$ in $E$. coli, the strict surrounding sequence requirements and features of the adjacent loop and helix can explain much of the specificity (Motorin et al. 1997); however, for many others there is little or no information.
Another active area concerns the precise role of individual subunits of multisubunit processing enzymes. For $\mathrm{m}^{1} \mathrm{~A}$ methyltransferase, which is catalyzed by Gcd10p/ Gcd14p, it seems likely that Gcd10p directs binding of tRNA and Gcd14p binds the required cofactor $S$-adenosylmethionine (Anderson et al. 2000). However, for the adenosine deaminase $\operatorname{Tad} 2 \mathrm{p} / \mathrm{Tad} 3 \mathrm{p}$ complex, both members of which share significant homology, there is no such clean split of functions. Mutational analysis indicates that Tad2p is the catalytic subunit, but both subunits appear necessary for binding (Gerber and Keller 
1999). Still more complicated is the tetrameric splicing endonuclease of yeast, which like $\operatorname{Tad} 2 \mathrm{p} / \mathrm{Tad} 3 \mathrm{p}$, has two highly related subunits that are part of a widely conserved family. In this case each of the two related subunits, Sen $2 p$ and Sen $34 p$, catalyzes one of the two endonucleolytic excision steps, thus taking the place of the homodimeric splicing enzyme in other organisms (Kleman-Leyer et al. 1997; Lykke-Andersen and Garrett 1997; Trotta et al. 1997; Li et al. 1998a). The roles of the other two subunits of the yeast enzyme, Sen $15 \mathrm{p}$ and Sen54p, are unknown; in particular, there is no explanation for why the protein appears to be membrane-associated (Peebles et al. 1983; Trotta et al. 1997), and how tRNA recognition is accomplished. The largest complex in the yeast tRNA-processing pathway is RNase $\mathrm{P}$, which is comprised of at least nine essential protein subunits and one essential RNA subunit (Chamberlain et al. 1998). Its composition belies the relatively simple nature of the reaction, cleavage of the $5^{\prime}$ leader from pre-tRNA molecules (Fig. 1); indeed, the corresponding bacterial enzyme accomplishes the same goal with just one catalytic RNA subunit and one protein subunit (GuerrierTakada and Altman 1984). Although many of the details of the architecture of RNase P have been elucidated (Houser-Scott et al. 2002), the nature of the recognition domain and the catalytic domain is still unclear. Recently, it has been shown that the isolated Pop3p subunit binds pre-tRNAs tightly (Brusca et al. 2001). However, a precursor form of RNase $\mathrm{P}$ that lacks this subunit is active (Srisawat et al. 2002). Because this precursor form also lacks the only subunit that is unique between RNase $\mathrm{P}$ and the related nuclease RNase MRP, which is specific for rRNA and not tRNA, the suggestion has been made that the RNA subunit of RNase $\mathrm{P}$ is responsible for substrate specificity (Srisawat et al. 2002). Clearly, much remains to be done to elucidate precisely how this protein complex finds its substrates and catalyzes its activity, and the precise roles of the subunits in this function.

\section{Unraveling the elusive functions of tRNA modification}

Previous studies had indicated that although a few exceptional modifications were important for growth, the majority of tRNA modifications in yeast or other organisms had only modest effects on translation under defined circumstances, or had little or no measurable effects on growth. The failure to identify phenotypes of many modification mutants was distinctly unexpected, given their evolutionary conservation, the observation that almost all tRNAs have multiple modifications, and the fact that more than 80 modifications have been described in various organisms (Björk 1995; Sprinzl et al. 1998), and precluded further study of their function in meaningful ways. However, several examples of phenotypes of modification defects have now been described, which shed light on their roles.

For several modifications affecting the region around the anticodon, lack of the corresponding gene causes a distinct growth phenotype. Thus, slow growth is observed in strains lacking Pus3p, which modifies $\Psi 38$ and
$\Psi 39$ (Lecointe et al. 1998), Trm7p, which catalyzes 2'$O$-methylation at positions 32 and 34 (Pintard et al. 2002), or Trm5p, which catalyzes $m^{1} G$ and $m^{1} I$ formation at position 37 and the likely first step of Y-base formation (Björk et al. 2001). A translation defect is associated with the trm 7 mutants, and almost certainly with trm5 mutants, because the Trm5p homolog in E. coli is essential for reading frame maintenance (Urbonavicius et al. 2001). Similarly, each of the Tad2p and Tad3p subunits of the yeast tRNA A34 deaminase is essential, presumably to ensure that the wobble nucleotide can correctly pair with the mRNA codons during translation (Gerber and Keller 1999). In contrast, mod5 mutants, which lack $i^{6} \mathrm{~A}$ at position 37 in three cytoplasmic and two mitochondrial tRNAs, have no discernible phenotype other than altering efficiency of tRNA-mediated nonsense suppression (Laten et al. 1978). Surprisingly, the proteins for $\mathrm{m}^{1} \mathrm{~A} 58$ formation are also essential in yeast (Garcia-Barrio et al. 1995; Calvo et al. 1999), although this modification occurs well away from the critical anticodon loop.

For most other modifications, mutant phenotypes have been more difficult to find, until recent application of more sensitive assays. One such case concerns E. coli $\operatorname{tru} B$ mutants, which are defective in $\Psi 55$ formation. These mutants have almost no measurable phenotype in liquid culture, which is surprising because $\Psi 55$ is almost universally found in the cytoplasmic tRNAs of all organisms as part of the highly conserved T $\Psi$ C loop from nucleotides 54-56. Ofengand and coworkers /Gutgsell et al. 2000) have used competitive growth to demonstrate a distinct growth phenotype of $E$. coli tru $B$ mutants. When cocultured with wild-type strains through successive cycles of growth, these mutants are relatively rapidly lost, at a rate of a few percent per complete growth cycle (Gutgsell et al. 2000). Remarkably, this competitive growth defect of $\operatorname{tru} B$ mutants could be complemented by a strain carrying a catalytically inactive truBp variant, demonstrating that there is some other function of TruB, possibly a chaperone function, that is responsible for the growth defect, rather than the $\Psi 55$ modification itself. A similar competitive growth defect was previously reported for mutants lacking RluAp, which is responsible for formation of $\Psi 32$ in tRNA as well as for two $\Psi$ modifications in rRNA (Raychaudhuri et al. 1999).

A different approach using a synthetic (genetic interaction) screen recently demonstrated a phenotype for yeast pus4 mutants, which lack $\Psi 55$. In a synthetic lethal screen, a single mutant with no obvious phenotype is used to search for a second mutant that causes the cell to be sick or dead. In this way, a screen with pus1 mutants, which lack many different $\Psi$ residues in their tRNAs (Table 1), revealed that pus1 pus4 double mutants are lethal, or slow growing and temperature-sensitive, depending on the exact background (Grosshans et al. 2001), as are pus1 mutants that also have a defective minor tRNA species. Although it is not clear yet exactly how the pus 4 defect contributes to lack of viability of these double mutants, this result demonstrates the use of synthetic screens to expose otherwise subtle effects, 
and provides a starting point for further genetics and cell biology experiments.

A similar synthetic screen was used by Johansson and Byström (2002) to explore the function of yeast Trm2p, which encodes the $\mathrm{m}^{5} \mathrm{U} 54$ methyltransferase that forms $\mathrm{T}$ in the highly conserved T $\Psi \mathrm{C}$ loop of tRNAs. Their results demonstrated a synthetic interaction between trm2 mutants and a sup61 mutant specifying an altered tRNA $_{\mathrm{CGA}}{ }^{\text {Ser }}$, which was correlated with lower than normal levels of the mutant tRNA. A series of tests showed similar growth defects in sup61 trm1, sup61 trm3, and sup61 pus4 double-mutant strains, all correlated with lower levels of tRNA $\mathrm{CGA}^{\text {ser }}$, and no synthetic effects in sup61 rit1 strains. Because all of the genes showing synthetic effects with sup61 mutants are also involved in modification of this tRNA, and Ritlp is not involved in modification and has no synthetic effect, it seems likely that the growth defect is caused by direct interaction of these proteins with the tRNA. As described above with truB mutants, and observed earlier for the E. coli TrmA $\mathrm{m}^{5} \mathrm{U} 54$ methyltransferase (Persson et al. 1992), the growth defect of sup61 trm2 mutants could be partially complemented by expression of a catalytically inactive $\operatorname{Trm} 2$ protein, demonstrating a separate role of Trm $2 p$ distinct from its modification activity. It is not known if expression of catalytically inactive Trm1, Trm3, and Pus4 proteins will also complement their synthetic growth defects.

The essential function of $\mathrm{m}^{1} \mathrm{~A} 58$ modification that is catalyzed by Gcd10p/Gcd14p also appears to be caused by lowered tRNA levels, but remarkably, by only one of the 17 tRNA species that has this modification, tRNA $_{i}{ }^{\text {Met }}$ (Anderson et al. 1998, 2000). Three lines of evidence support this claim: high copies of this tRNA (but not the elongator tRNA ${ }^{\text {Met }}$, which also has this modification) rescued the lethal phenotype of a gcd14- $\Delta$ strain; a gcd14 mutant had reduced levels of tRNA ${ }_{i}{ }^{\text {Met; }}$; and a gcd10 mutant coordinately exacerbates both the growth defect and the $\mathrm{tRNA}_{\mathrm{i}}{ }^{\mathrm{Met}}$ expression of a gcd14 mutant (Anderson et al. 1998; Calvo et al. 1999).

In sum, the data indicate that many tRNA modifications at positions other than the anticodon and/or the corresponding modification proteins have a role in the stability of mature tRNAs.

\section{New connections between tRNA processing, translation, and other metabolic pathways}

Recent experiments have also shown a large number of new and intriguing connections between parts of the tRNA-processing pathway and the translation machinery as well as other pathways in the cell.

\section{Translation}

As discussed above, it is well known that a number of tRNA modification genes, particularly those affecting the region around the anticodon, exert their effects by altering translation at steps within the ribosome (see Ur- bonavicius et al. 2001). However, recent experiments indicate other connections between tRNA processing and translation.

Recent evidence indicates a new link between the modification of $\mathrm{tRNA}_{\mathrm{i}}{ }^{\text {Met }}$ by Ritl protein and the translation initiation machinery. Rit1 protein adds a 2'-Oribosyl phosphate to position 64 of $\mathrm{tRNA}_{\mathrm{i}}{ }^{\mathrm{Met}}$, which is the only tRNA bearing this modification (Åström and Byström 1994). rit1 mutants have synthetic growth defects with mutations that either lower the number of initiator tRNA genes or perturb any of the subunits of eIF-2. Because eIF-2 is responsible for delivering tRNA $_{i}{ }^{\text {Met }}$ to the $43 \mathrm{~S}$ ribosome to initiate translation, this set of results implies that growth defects arise from any combination that lowers the amount of the eIF-2tRNA $_{i}{ }^{\text {Met }}$ complex, or the quality of $\mathrm{tRNA}_{\mathrm{i}}{ }^{\mathrm{Met}}$ in the complex. Consistent with this argument, overproduction of initiator tRNA genes can reverse the synthetic growth defect caused by rit1 eIF-2 subunit double mutants, and overproduction of eEF1 $\alpha$ can sequester tRNA $_{i}{ }^{\text {Met }}$ that does not have the 2'-O-ribosyl phosphate and exacerbate formation of the complex (Åström et al. 1999).

An unexpected link has also been established between the status of tRNA processing in the nucleus and GCN4 mRNA translation in the cytoplasm, because mutations that lead to $5^{\prime}$ - or $3^{\prime}$-end-processing defects in the nucleus can induce GCN4 mRNA translation (Qiu et al. 2000). Thus, GCN4 mRNA translation can be induced by overexpression of either NME1, encoding the RNA subunit of RNase MRP (Tavernarakis et al. 1996), or of PUS4, encoding $\Psi 55$ pseudouridylase (Qiu et al. 2000), and both phenotypes are correlated with increased accumulation of pre-tRNAs. Three lines of evidence link this pre-tRNA accumulation to a nuclear location: First, an altered tRNA ${ }^{\mathrm{Val}}$ that cannot be processed at its $3^{\prime}$ end, and which causes GCN4 mRNA translation, is localized to the nucleus. Second, overproduction of the yeast exportin-t Los 1 protein, which would be expected to move cargo to the cytoplasm, adversely affects GCN4 translation, and los 1 mutants act to enhance GCN4 translation. Third, overexpression of PUS4 leads to nuclear accumulation of at least one tRNA, and this effect is abrogated by overexpression of LOS1. These results all support the argument for a surveillance mechanism in the nucleus that somehow conveys information to the translation machinery in the cytoplasm about the state of tRNA processing (Qiu et al. 2000).

\section{Multiple effects of $i^{6} \mathrm{~A}$}

One striking observation is the effect of $i^{6} \mathrm{~A}$ formation, or of the protein that catalyzes the corresponding reaction, on multiple pathways. The protein Mod5, $\Delta^{2}$-isopentenyl pyrophosphate:tRNA isopentenyl transferase, catalyzes transfer of the isopentenyl group from dimethylallyl pyrophosphate to A37 of certain tRNAs to form $i^{6} \mathrm{~A}$ (Dihanich et al. 1987), and mod5 mutants have lower translation efficiency in yeast strains with suppressor tRNAs such as SUP7 (Laten et al. 1978). Recent experi- 
ments indicate that Mod5p or its product $\mathrm{i}^{6} \mathrm{~A}$ can affect several processes. First, Benko et al. (2000) have shown that the yeast enzyme Mod5p is in competition with Erg20p for their common substrate dimethylallyl pyrophosphate. Given that Erg20p catalyzes formation of geranyl pyrophosphate and farnesyl pyrophosphate, the precursors for sterols, prenylated proteins, uniquinone, dolichol, and HemeA, this result implies that a strict balance between the two proteins must be maintained to properly funnel dimethylallyl pyrpophosphate (Benko et al. 2000). Second, mutations in the Caenorhabditis elegans GRO-1 gene, which encodes a highly related presumed MOD5 ortholog, grow slowly and have an increased life span (Lemieux et al. 2001). Like Mod5p in yeast (Boguta et al. 1994), GRO1 protein is found in the nucleus, cytoplasm, and mitochondria; only the mitochondrial form of the protein is required to complement the gro1 defect (Lemieux et al. 2001). Third, there may also be a connection between $\mathrm{i}^{6} \mathrm{~A}$ modification and selenocysteine tRNA. Thus, transient transfection of a mutant tRNA ${ }^{[\text {Ser]Sec }}$ gene carrying a change at the 37 position, the site normally modified to $\mathrm{i}^{6} \mathrm{~A}$, causes the repression of translation of the cotransfected gene for the selenoprotein deiodinase (Warner et al. 2000). Addition of lovastatin, a drug that prevents formation of mevalonate (the precursor of the isopentenyl moiety), has the same effect, and also represses synthesis of endogenous selenoproteins (Warner et al. 2000).

\section{RNase P and RNase MRP}

The connection between RNase P and RNase MRP is underscored by the large number of shared components between the two proteins (Chamberlain et al. 1998). Each protein in yeast has nine polypeptide subunits and one RNA subunit, and eight of the nine subunits are identical. That RNase P and RNase MRP have an impact on each other in $S$. cerevisiae is evident by the apparent competition of their RNA components, NME1 and RPR1, for protein components, as measured by their competing effects for induction of GCN4 mRNA translation (Qiu et al. 2000). Whereas the direct role of RNase $\mathrm{P}$ is to endonucleolytically remove the $5^{\prime}$ trailer from all tRNA transcripts, RNase MRPs have been implicated in processing 5.8S rRNA, as well as in exit from mitosis and various other roles (see Cai et al. 2002 and references therein). In sum, RNase P/RNase MRP balance can affect a number of processes in the cell.

\section{tRNA splicing machinery in the unfolded protein response}

The observation by the Walter lab that the unfolded protein response in yeast is mediated by a unique tRNA-like splicing event is another striking example of the sharing of an RNA processing pathway with an unanticipated, seemingly unrelated pathway. The unfolded protein response, which is activated by any of several stress treatments, leads to expression of the transcription factor
Haclp in yeast, which in turn activates expression of a number of downstream targets. Remarkably, expression of Haclp in yeast is mediated by a tRNA-like splicing of HAC1 mRNA, using an endonuclease activity of Irelp, and ligation by the yeast tRNA splicing ligase (Sidrauski et al. 1996; Sidrauski and Walter 1997; Gonzalez et al. 1999) to remove the inhibitory function of the intron on translation of Haclp (Ruegsegger et al. 2001). This unusual splicing reaction is also observed in mammals when yeast HAC1 is expressed during the mammalian unfolded protein response (Niwa et al. 1999), and recently a true substrate-spliced mRNA has been found in both C. elegans and mice (Calfon et al. 2002). Therefore, at least some mRNA splicing occurs by a tRNA splicing mechanism in eukaryotes, sharing some of the tRNA splicing machinery, and factors that influence tRNA ligase may also regulate this class of splicing.

\section{News about tRNA-processing mechanisms}

Several recent experiments using different organisms have resulted in new insights into tRNA-processing biochemistry, and revealed unexpected diversity in tRNAprocessing biochemistry. These are described below.

\section{Elusive 3'-end-processing machinery}

The mysterious mechanism by which 3 ' ends of tRNAs are generated in eukaryotes and prokaryotes appears to be unfolding. It is known from earlier work in E. coli that several 3' exonucleases can contribute to maturation of tRNAs, particularly RNase II and PNPase in trimming the longer $3^{\prime}$ trailers, and RNase $\mathrm{PH}$ and RNase $\mathrm{T}$ in trimming the last few nucleotides $(\mathrm{Li}$ and Deutscher 1994, 1996). However, the endonuclease has been elusive. Recent work by two groups has demonstrated that RNase $E$ is likely the initial endonuclease that triggers subsequent tRNA processing, as demonstrated for a large number of different tRNA species in different types of operon contexts (Li and Deutscher 2002; Ow and Kushner 2002).

The 3 '-end-processing machinery in eukaryotes is much more poorly understood, and is also complicated by multiple implicated endonucleases and exonucleases. In yeast two endonucleases and 3 ' exonuclease activities have been partially purified (Papadimitriou and Gross 1996), and it is known that the yeast La protein, Lhplp, is required for endonucleolytic processing of tRNAs, because strains without Lhplp process tRNAs via exonucleases (Yoo and Wolin 1997). However, the identity of the endonuclease has been a mystery, because there is no indication that Lhplp has endonuclease activity. Recently, Marchfelder and colleagues have identified a likely candidate from Arabidopsis thaliana and Methanococcus jannaschii, after analysis of the peptide sequences of a purified wheat protein (Schiffer et al. 2002). Expression of these proteins, called RNase Z, in E. coli results in extracts that can catalyze the same endonuclease reaction that was obtained from wheat germ, 
namely, cleavage $3^{\prime}$ to the discriminator. This protein appears to be conserved in humans and in S. cerevisiae. It will be interesting to determine the function of this gene in vivo.

\section{The puzzle of CCA addition}

One longstanding conceptual problem is how CCA is added to the ends of tRNA in a precise fashion, without benefit of a template. Work in several labs has led to new views of how the CCA-adding enzyme accomplishes this feat. An original model depicted this enzyme as having three nucleotide-binding sites for progressive addition of the three nucleotides (Deutscher 1972). More recently, several different models have been proposed, based on a variety of experiments. Work from the Weiner lab has resulted in a new view of this protein as one with a single active-site pocket, whose active site appears to be recreated during the course of each addition reaction by refolding at the $3^{\prime}$ end of the tRNA. This model is based on the observation by Yue et al. (1998) that the Sulfolobus shibatae enzyme likely has a single active site, because mutation at either of two predicted critical Asp residues, identified by alignment, completely abolishes both $\mathrm{C}$ and $\mathrm{A}$ addition activities. Furthermore, there is strong evidence that the tRNA substrate is fixed to its protein for addition of the terminal $\mathrm{C}$ and $\mathrm{A}$ residues, because phosphate interference experiments demonstrate a requirement for the same phosphates for addition of $\mathrm{C}$ to tRNA-C as for addition of A to tRNA-CC, for both the $E$. coli enzyme and the $S$. shibatae enzyme, and because the $S$. shibatae enzyme is active for both addition reactions when cross-linked (Shi et al. 1998). It therefore seems likely that the active site reforms in collaboration with the growing 3' end in the same pocket (Yue et al. 1998). A second model posits the existence of two nucleotidebinding sites, one catalytic CTP site and one ATP site that is both regulatory and catalytic (Hou 2000), to account for the observation that the $E$. coli enzyme can add more than the normal number of $\mathrm{C}$ residues in the absence of ATP, but not in its presence. A third model has been proposed by Steitz and coworkers (Li et al. 2000), based on the observation of tRNA-induced tetramer formation by the $S$. shibatae CCA-adding enzyme with only two tRNA molecules bound per tetramer. This halfof-the-sites occupancy by tRNA substrates led to the proposal of a scrunch-shuttling model according to which two proteins of each tetramer have adjacent active sites that are responsible for $\mathrm{C}$ addition and $\mathrm{A}$ addition, respectively. Addition of two $\mathrm{C}$ residues would require scrunching at one active site, after which the $3^{\prime}$ end would shuttle to the neighboring active site for addition of A (Li et al. 2000). Recently, it has been found that the eubacterium Aquifex aeolicus has separate enzymes for addition of CC and of A, as demonstrated by homology searches, activity assays, and function in E. coli strains lacking the CCA-adding enzyme (Tomita and Weiner 2001). This finding could be viewed as supporting an argument for separate sites for $\mathrm{C}$ addition and $\mathrm{A}$ addition in the E. coli and S. shibatae enzymes, or as a more primordial form of the enzyme. The true nature of the active site and the solution of this puzzle await the three-dimensional structure of the enzyme, and other chemical tests.

\section{Splicing conserved at the outset but not at the end?}

As described above, the groundbreaking work of the Abelson and Daniels labs led to the identification of related genes encoding part of the splicing endonuclease in yeast (Trotta et al. 1997) and the Haloferax volcanii protein (Kleman-Leyer et al. 1997), which then led directly to the rapid identification of orthologs in a number of archaeal, vertebrate, and plant species (Lykke-Andersen and Garrett 1997; Fabbri et al. 1998). Curiously, however, increasing evidence suggests that the subsequent ligation steps may not be conserved. The yeast ligation pathway is known to require two components: tRNA ligase (Trllp), to join the excised exons forming a splice junction 2'-phosphate (Phizicky et al. 1992), and the 2'phosphotransferase Tptlp to transfer the phosphate to NAD to form ADP-ribose 1"-2"-cyclic phosphate (Culver et al. 1993; Spinelli et al. 1997). Similar ligase activities have been found in plants and humans (Konarska et al. 1982; Pick and Hurwitz 1986; Zillman et al. 1991), and Tptlp activity or functional orthologs have been found widely in plants, vertebrates, and archaea (Zillman et al. 1992; Spinelli et al. 1998; Yukawa et al. 2001). However, the ligation pathway in some organisms may involve a completely different ligase, first discovered some time ago in vertebrates (Nishikura and De Robertis 1981; Filipowicz and Shatkin 1983; Laski et al. 1983), that does not produce a 2 -phosphate junction. Two papers describing a vertebrate-like ligase in $H$. volcanii have rekindled the argument for a division of this metabolic pathway into two branches of ligation /Gomes and Gupta 1997; Zofallova et al. 2000).

Equally curious, a functional Tptlp ortholog is also found in bacteria such as E. coli. The E. coli 2 '-phosphotransferase has the same activity as the yeast enzyme in vitro, can substitute for the yeast enzyme in vivo (Spinelli et al. 1998), and has almost the same substrate specificity requirements in vitro, and very similar kinetic parameters (Steiger et al. 2001). This is highly unexpected because there is no known ligase in E. coli that generates a junction 2'-phosphate, and no known RNA with this structure. However, the fact that the bacterial protein has been conserved through 3 billion years of evolution suggests that there is some related activity that it can catalyze or a related substrate upon which it acts. By extension, there may be a second function for the 2 -phosphotransferase in yeast in addition to its known role in removing the 2 '-phosphate from ligated tRNA (Spinelli et al. 1997), and a corresponding function in other eukaryotes.

\section{A multitude of tRNA editing/ modification mechanisms}

Many recent experiments have uncovered extensive editing mechanisms in tRNAs, several of which were a 
distinct surprise. One of the most unusual mechanisms of tRNA processing appears to require rebuilding the $5^{\prime}$ end of mitochondrial tRNAs in Acanthamoeba castellanii. All but three of the likely mitochondrial tRNAs in this organism have mismatches in one or more of the first three base pairs of the aminoacyl stem that would appear to require posttranscriptional alteration of the $5^{\prime}$ portion of the acceptor stem (Lonergan and Gray 1993; Burger et al. 1995). Experiments using crude extracts are consistent with the hypothesis that the $5^{\prime}$ ends of bulk tRNA and of model substrates are remodeled by removal of as many as three nucleotides at the $5^{\prime}$ end of the RNA, followed by the incorporation of nucleotides in the presence of ATP to reform a paired aminoacyl acceptor stem (Price and Gray 1999). This may be the first case of an authentic template-dependent polymerase that can add nucleotides in the $3^{\prime}$-to-5' direction.

Other reports detail unusual editing mechanisms at the $3^{\prime}$ end. It has been known for several years that mitochondrial tRNAs can be edited at their $3^{\prime}$ ends in either of two template-independent ways, as judged by comparison of the sequences of cDNAs of circularized tRNA with that of the mitochondrial genome. Several animals such as land snail, chicken, and squid appear to have evolved a mechanism that formally corresponds to polyadenylation to fill in the end of the aminoacyl acceptor stem through to the discriminator position (see Fig. 1), presumably after processing of the tRNA precursor from its downstream overlapping gene (Yokobori and Paabo 1995a, 1997; Tomita et al. 1996). In contrast, platypus has evolved a mechanism in which the $3^{\prime}$ end is changed by introduction of two specific $\mathrm{C}$ residues in the acceptor stem and an A residue at the discriminator position, apparently in a template-independent manner, before the terminal CCA addition (Yokobori and Paabo 1995b). Recently, analysis of the mitochondrial tRNAs of the centipede Lithobius forficatus shows that for all but one of its 22 tRNA genes there is an apparent template-dependent editing requirement to fill in the aminoacyl acceptor stem and the discriminator base $A_{\text {; }}$ presumably this reaction requires an RNA-dependent RNA polymerase (Lavrov et al. 2000). Because all of these mechanisms are inferred from comparison of cDNA sequences with genomic sequence, each mechanism assumes that these cDNAs represent true tRNA-processing intermediates, rather than side products or dead-end products of this or another processing pathway. There is clearly more work necessary to prove this assumption is true and then to unravel these interesting tRNA-processing reactions.

Several previously described editing classes are also manifested in mitochondrial tRNA. The most prevalent of these editing events involves a C-to- $\mathrm{U}$ alteration corresponding to the likely deamination of cytidine. This type of editing was first observed in a marsupial tRNA ${ }^{\text {His }}$ (Janke and Paabo 1993) and in plants (Marechal-Drouard et al. 1993; Binder et al. 1994), and appears in several cases to be required for processing of the corresponding tRNAs (Marchfelder et al. 1996; Marechal-Drouard et al. 1996a,b). C-to-U editing also occurs in Leishmania tarentolae, where it appears to occur only when the tRNA is imported into the mitochondria (Alfonzo et al. 1999). Classical insertional editing of cytidine and uridine residues has also been observed in a number of mitochondrial tRNAs of Physarum polycephalum and Didymium nigripes (Antes et al. 1998).

One new twist of tRNA processing is the finding of a guide-RNA-mediated tRNA modification that is selfguided. A euryarchaeal tRNA ${ }^{\operatorname{Trp}}$ gene carries within its intron a box-C/D guide RNA motif specifying its own 2'-O-methylation at two positions (d'Orval et al. 2001). In eukaryotes and some archaea, the box-C/D motif specifies fibrillarin binding, and together with adjacent RNA sequences that pair to the target RNA, directs 2'$O$-methylation at sites within the paired region (see Smith and Steitz 1997). This tRNA ${ }^{\text {Trp }}$ and the corresponding intron-containing motif specifying $2^{\prime}$-O-methylation is found in several euryarchaeal species, and extracts from $H$. volcanii can faithfully reproduce the two ribose methylations in a manner that requires elements of the intron. This is the first example of a possible cisacting methylation guide function, and the first such guide-modulated 2'-O-methylation reaction that has been reproduced in vitro.

\section{tRNA quality control}

Work in the Deutscher lab has uncovered a new dimension of tRNA biogenesis in E. coli, control of its quality by degradation of tRNAs that are incompletely $3^{\prime}$-end processed. Two lines of evidence support this claim. First is the demonstration that tRNA precursors (and other small stable RNAs) can be polyadenylated when tRNA maturation is deliberately slowed because of mutation of processing exonucleases ( $\mathrm{Li}$ et al. 1998b). Because polyadenylation of mRNA (O'Hara et al. 1995) and a regulatory RNA (Xu et al. 1993) in E. coli has been linked to RNA degradation, polyadenylation of tRNAs may also trigger their degradation. Second is the demonstration that a tRNA ${ }^{\mathrm{Tr}}$ species with a mutation conferring a temperature-sensitive phenotype accumulates increased amounts of precursor tRNA in cells lacking poly(A) polymerase (Li et al. 2002). Because the precursor tRNAs did not accumulate in the corresponding strains with wild-type tRNA, and because even larger amounts of pre-tRNAs were observed in cells also lacking polynucleotide phosphorylase, which had previously been implicated as a degradative enzyme for mRNA (Xu et al. 1993; Carpousis et al. 1999), the implication from these studies is that misfolded tRNA precursors are subject to degradation, just as mRNAs are normally degraded in E. coli.

\section{Surprising complexity for the nuclear organization of the tRNA-processing pathway(s)}

\section{Distinct preferred pathways for different organisms}

Studies using pulse-labeled yeast cells and microinjected Xenopus oocytes that assessed appearance of tRNA-processing intermediates and presence of modified nucleo- 
sides on these pre-tRNAs provided the first lines of evidence for the multistep reactions occurring in a preferred order (Etcheverry et al. 1979; Melton et al. 1980; Nishikura and De Robertis 1981). Surprisingly, the order of pre-tRNA-processing steps appears to differ among organisms; for example, in budding and fission yeast, end processing usually precedes splicing $\left(\mathrm{O}^{\prime}\right.$ Connor and Peebles 1991; for review, see Wolin and Matera 1999; Intine et al. 2002), whereas in Xenopus oocytes splicing precedes end processing (Lund and Dahlberg 1998).

Theoretically, ordered pathways could result from processing enzyme substrate specificities. In fact, there are clear examples of this. For instance, the enzymes that modify $\mathrm{C}$ to $\mathrm{m}^{5} \mathrm{C}$ and $\mathrm{U}$ to $\Psi$ of tRNA anticodon loops require intron-containing pre-tRNA, and these steps must occur prior to pre-tRNA splicing (Johnson and Abelson 1983; Szweykowska-Kulinska et al. 1994; for review, see Grosjean et al. 1997). Other modification activities use spliced tRNAs as substrates, and the resulting modifications occur only after splicing (Melton et al. 1980; Nishikura and De Robertis 1981; Grosjean et al. 1997; Spinelli et al. 1997).

Substrate specificity, however, does not provide an explanation for the ordering of the majority of tRNA-processing steps. Genetic and biochemical studies show that most tRNA biogenesis steps are not obligatorily ordered. For example, mutations of yeast genes encoding tRNA modification activities generally affect only the single nucleoside modification in question (Phillips and Kjellin-Stråby 1967; Hopper et al. 1982; Åström and Byström 1994; Anderson et al. 1998; Lecointe et al. 1998; Motorin et al. 1998; Cavaille et al. 1999; Motorin and Grosjean 1999; Nordlund et al. 2000; Pintard et al. 2002). Likewise, in vitro generated unmodified tRNAs generally serve as substrates for purified tRNA modification activities (Åström and Byström 1994; Becker et al. 1997; Anderson et al. 1998; Gerber et al. 1998; Cavaillé et al. 1999; Motorin and Grosjean 1999; Alexandrov et al. 2002; Pintard et al. 2002; Xing et al. 2002). In fact, we are unaware of a single example for which the addition of a given tRNA modification requires previous addition of a modification at a different location. Similarly, in wild-type yeast cells, RNase P generally removes tRNA 5' ends prior to endonucleolytic cleavage at $3^{\prime}$ termini $\left(\mathrm{O}^{\prime}\right.$ Connor and Peebles 1991; Yoo and Wolin 1997). However, in cells lacking the tRNA-binding La protein, a $3^{\prime}$ exonuclease usually acts prior to RNase $\mathrm{P}$, changing the order of processing steps for many pre-tRNAs (Yoo and Wolin 1997). Moreover, in wildtype yeast, for at least tRNA ${ }^{\operatorname{Trp}}, 3^{\prime}$ processing precedes $5^{\prime}$ processing (Kufel and Tollervey 2003). Therefore, the preferred order of $5^{\prime}$ processing before $3^{\prime}$ processing is not obligatory. Finally, the order of splicing versus end processing is not requisite because for both yeast and Xenopus oocytes the ordered paths can be reversed (Lund and Dahlberg 1998; Intine et al. 2002).

\section{Location, location, location}

The tRNAs that function in cytosolic protein synthesis appear to be processed at several locations-at multiple subnuclear sites as well as in the cytosol-and this partitioning may influence ordering of tRNA biogenesis steps. In the nucleus there is little evidence for tRNA processing occurring at transcription sites, unlike for pre-mRNA processing, which occurs cotranscriptionally via recruitment of processing activities to sites of mRNA transcription (for review, see Maniatis and Reed 2002). The La protein, involved in tRNA end maturation, is the only protein involved in tRNA processing that has been implicated in transcription, but its role in transcription remains controversial (for reviews, see Maraia and Intine 2002; Wolin and Cedervall 2002). Most other tRNA-processing proteins are concentrated at locations distinct from sites of transcription. Assuming that those sites of concentrations reflect sites of biochemical activity, it would appear that tRNAs are processed at several subnuclear locations.

The nucleolus, the location for rRNA transcription, processing, and ribosome assembly, also harbors some tRNA biosynthetic activities. For example, in budding yeast the RNA subunit of RNase $\mathrm{P}$ is primarily nucleolar (Bertrand et al. 1998). In contrast, the human RNA homolog appears to be distributed throughout the nucleoplasm (for review, see Jarrous 2002). As detailed above, most of the RNase P protein subunits are shared with RNase MRP functioning in pre-rRNA processing (for review, see Xiao et al. 2002). Therefore, the location of yeast RNase $\mathrm{P}$ in the nucleolus allows dual participation of proteins in rRNA and tRNA biogenesis. RNase $\mathrm{P}$ is not the only yeast tRNA-processing enzyme in the nucleolus, as a portion of the Mod5p-II pool has been reported to be located there (Tolerico et al. 1999). As rRNAs and snoRNAs do not appear to possess $i^{6} \mathrm{~A}$, it is unclear why Mod5p should be located in the nucleolus or even if it is active at this location. Consistent with the idea that part of the tRNA-processing pathway occurs in the nucleolus, some, but not all, intron-containing pretRNAs are located in the nucleolus (Bertrand et al. 1998; Sarkar and Hopper 1998; Grosshans et al. 2000).

Numerous nuclear tRNA biosynthetic enzymes are concentrated at subnuclear sites other than the nucleolus. For example, S. cerevisiae and Schizosaccharomyces pombe Puslp, which catalyzes $U$ to $\Psi$ at several tRNA locations and at position 44 of U2 snRNA, is distributed throughout the nucleoplasm (Simos et al. 1996; Motorin et al. 1998; Massenet et al. 1999; Hellmuth et al. 2000). In contrast, yeast Trm 1 p-II, encoding $\mathrm{m}_{2}{ }^{2} \mathrm{G}$ methyltransferase, and Trm $4 p$, encoding tRNA specific $\mathrm{m}^{5} \mathrm{C}$ methyltransferase, are located at the inner nuclear membrane (INM; Li et al. 1989; Rose et al. 1995; Wu et al. 1998; Motorin and Grosjean 1999).

Yeast tRNA splicing endonuclease that catalyzes pretRNA intron removal purifies as an integral membrane heterotetrameric complex (Peebles et al. 1983; Trotta et al. 1997). It is widely believed that this membrane is the INM because pre-tRNA splicing is an intranuclear process in Xenopus oocytes (Melton et al. 1980) and because in budding yeast intron-containing pre-tRNAs appear to be located solely within the nucleus (Sarkar and Hopper 1998; Grosshans et al. 2000). However, the INM location 
of tRNA splicing endonuclease has not yet been verified by microscopy. Even though, as assessed by indirect immunofluorescence and by electron microscopy, tRNA ligase that joins the cognate tRNA halves after splicing is located predominantly at the INM, there are nucleoplasmic and active cytosolic pools of this enzyme as well (Clark and Abelson 1987; Ruegsegger et al. 2001). The cytosolic pools appear to be involved in the unfolded protein response pathway described above. Despite the complexities, the most straightforward, but as yet unproven, conclusion from the yeast studies is that pretRNA intron removal occurs at the INM.

Modifications of the anticodon loop are among tRNAprocessing steps that occur in the cytosol as these modifications appear only after splicing and, in Xenopus oocytes, are added only when substrates are introduced into the cytosol (Etcheverry et al. 1979; Nishikura and De Robertis 1981). Indeed, the majority of budding yeast Mod5p-II, responsible for modification of $\mathrm{A}_{37}$ to $\mathrm{I}^{6} \mathrm{~A}$, is cytosolic (Boguta et al. 1994). Likewise, Trm7p, catalyzing methylation of ribose moieties at anticodon loop positions 32 and 34, and Pus6p, catalyzing formation of $\Psi$ at position 31 , have been reported to be largely cytosolic (Ansmant et al. 2001; Pintard et al. 2002).

In sum, substrate specificity can provide an explanation for the ordering of only a few of the steps of tRNA biogenesis. Rather, as tRNA biosynthetic activities appear to be spatially organized with several distinct subnuclear as well as cytosolic locations, it is likely that these cell biological constraints provide a major contribution to the preferred tRNA-processing order. However, there is insufficient information regarding whether the ordered events do, in fact, correlate with the subnuclear locations of the processing enzymes. Furthermore, at present there are no reports of the consequences of mislocating processing activities to alternative subnuclear locations on the order of processing steps. However, shifting $S$. pombe La protein from mostly nuclear to mostly cytosolic resulted in an altered processing order with pre-tRNA intron removal preceding 5 '- and 3 '-end maturation (Intine et al. 2002). If future studies to redistribute activities within the nucleus change tRNA-processing order, this would provide evidence that tRNAs travel to different subnuclear locations during maturation, a fundamentally different mechanism than for mRNA biogenesis.

\section{Moving tRNAs around the cell}

Although it has been long appreciated that eukaryotic cells possess mechanisms for delivering tRNAs from the nucleus to the cytosol, it has become obvious recently that the nuclear/cytoplasmic pathway is much more complicated than previously thought. In addition, it has become clear that cells also possess mechanisms for delivering tRNAs from the cytosol to mitochondria. Here we summarize present understanding of the mechanisms to accurately and efficiently move tRNAs around the cell.

\section{Aminoacylation likely serves a proofreading role for tRNA nuclear export}

Lund and Dahlberg (1998) provided paradigm-shifting data showing that tRNAs are aminoacylated while in the nucleus, and that nuclear tRNA aminoacylation facilitates, but is not essential for tRNA nuclear export in Xenopus oocytes (Arts et al. 1998b; Lund and Dahlberg 1998). Nuclear tRNA aminoacylation likely provides a proofreading step to ensure export of mature tRNAs to the cytosol because aminoacyl tRNA synthetases provide amino acids only to tRNAs possessing mature 3' termini (Lund and Dahlberg 1998). Nuclear tRNA aminoacylation also occurs in $S$. cerevisiae, where it also facilitates tRNA export (Sarkar et al. 1999; Grosshans et al. 2000), and nuclear pools of aminoacyl-tRNA synthetases have been verified both for vertebrate and yeast cells (Ko et al. 2000; Nathanson and Deutscher 2000; Azad et al. 2001; Galani et al. 2001). As aminoacylation of tRNAs was previously thought to occur solely in the cytosol, its occurrence also in the nucleus expands the known roles of the nucleus to include part of the translation process. Whether translation itself occurs in the nucleus remains controversial (Dahlberg et al. 2003). Despite the importance of nuclear aminoacylation of tRNA, it is unclear how nuclear aminoacylation fits into the tRNA export pathways described below.

\section{Exportin-t/Los1p-dependent tRNA nuclear export}

Movement of macromolecules between the nucleus and the cytoplasm is signal-mediated and often requires a small GTPase, Ran, its regulators, and members of the Ran-binding importin- $\beta$ family (for review, see Görlich and Kutay 1999). Importin- $\beta$ family members, in addition to binding to Ran, interact with NPC components and cargo and shuttle between the nucleus and cytosol. According to a simple model, a given importin- $\beta$ family member would provide unidirectional nucleus/cytosol movement for a specific subset of cargoes /Görlich and Kutay 1999). Some of the components of the tRNA nuclear export machinery, such as Loslp and Rnalp, were identified in yeast more than two decades ago by the effects of mutations in the corresponding genes on tRNA biogenesis (Hopper et al. 1978, 1980). However, their roles in the tRNA export process were first deciphered for the homologs in vertebrate cells.

A large body of literature now demonstrates that the vertebrate importin- $\beta$ family member exportin- $t$ and its yeast homolog Loslp serve to export tRNA from the nucleus to the cytosol (Fig. 2). Exportin-t directly binds tRNA in a Ran-GTP-dependent mechanism (Arts et al. 1998a; Kutay et al. 1998). Exportin-t also interacts with distinct nuclear pore proteins on the nucleoplasmic and the cytosolic nuclear surfaces, facilitating tRNA movement from the nuclear interior to the cytosol (Kuersten et al. 2002). In vitro studies showed that exportin-t interacts with $\sim 10$-fold higher apparent affinity with tRNAs possessing mature $5^{\prime}$ and $3^{\prime}$ termini than with tRNAs with terminal extensions or with tRNAs lacking 
Figure 2. Multiple pathways to export tRNA from the nucleus to the cytosol. On the left, the classical exportin-t/Los $1 \mathrm{p}$ tRNA nuclear export pathway shared between vertebrates and yeast is depicted. It is unclear whether tRNA aminoacylation is important for this pathway, and it is therefore indicated by a question mark. On the right, the Loslp-independent tRNA nuclear export possible mechanisms are depicted. Exportin-5 likely provides a minor tRNA nuclear egress route for vertebrates, but it is not clear whether its homolog, Msn5p, provides the same function for yeast. A major tRNA nuclear egress route for yeast is known to exist, and aminoacylation and Ccalp participate in this mechanism, but the details of their actions are not known and are indicated by question marks.

.

to
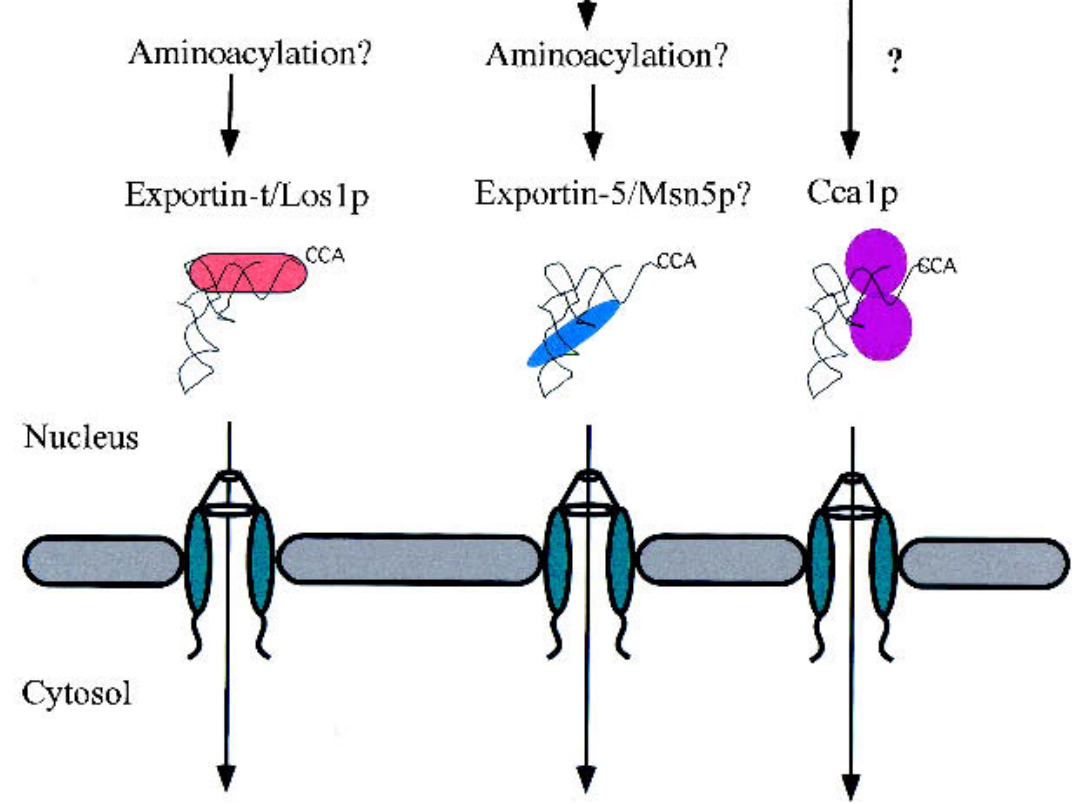

the 3' CCA nucleotides. Exportin-t interacts with $\sim 5$ fold higher apparent affinity with modified tRNAs than with in vitro generated unmodified tRNAs (Arts et al. 1998b; Lipowsky et al. 1999). Despite the fact that the relative in vitro binding affinities differences are not large, tRNAs with abnormal 5' and/or 3' termini or with mutations affecting the overall three-dimensional structure are exported inefficiently to the cytosol in Xenopus oocytes, providing supporting in vivo data that exportin-t substrate specificity provides a proofreading role to ensure nuclear export of end-matured tRNAs (Arts et al. 1998b; Lund and Dahlberg 1998; Lipowsky et al. 1999). However, exportin-t does not distinguish between intron-containing and spliced tRNAs (Arts et al. 1998b; Lipowsky et al. 1999). Export of only spliced tRNA to the cytosol in Xenopus oocytes results from the preferred processing order of splicing prior to end processing (Lund and Dahlberg 1998). It is unknown whether exportin-t binds preferentially aminoacylated, rather than uncharged tRNAs, thus the role of aminoacylation in this pathway requires further study.

Despite its well-described substrate specificity for mature $3^{\prime}$ tRNA termini, there is at least one indication that exportin-t may sometimes interact with tRNAs possessing 3' extensions. Chimeric tRNAs with 3'-attached ribozymes (tRNA-Rzs) have been reported to be efficiently exported to the cytosol in somatic cells, but not in Xenopus oocytes (summarized in Kuwabara et al. 2001). Based on exportin-t's substrate specificity (Arts et al. 1998b; Lipowsky et al. 1999), tRNA-Rz nuclear export would have been anticipated to be exportin-t-independent. Surprisingly, these chimeric molecules appear to interact with exportin-t in vitro, and tRNA-Rz export in somatic cells appears to be exportin-t-dependent, inconsistent with the prediction. One possible explanation is that weak interactions between exportin-t and tRNARZs might be sufficient for export.

Two lines of evidence show that $S$. cerevisiae Los $1 p$ is the yeast exportin-t homolog even though it has limited sequence similarity to exportin-t. First, los1 mutant cells accumulate nuclear pools of tRNA; and second, Los1p binds tRNA in an Ran-GTP-dependent manner (Hellmuth et al. 1998; Sarkar and Hopper 1998). Although the tRNA-binding activity of Los $1 p$ has not been examined in detail, it has been assumed that Los 1p, like exportin-t, also preferentially interacts with tRNAs with mature $5^{\prime}$ and 3 ' termini and does not distinguish between introncontaining and spliced tRNAs. If this indeed proves true, then there must be an additional mechanism (see discussions below) in yeast to prevent nuclear export of unspliced pre-tRNAs. This is because, unlike for Xenopus oocytes, tRNA end processing usually precedes splicing in $S$. cerevisiae, preventing efficient use of the vertebrate kinetic pathway favoring interaction of exportin-t with already spliced pre-tRNAs.

\section{Redundant exportin-t/Los1p-independent tRNA nuclear export pathway(s)}

Exportin-t/Los1p does not provide the sole means by which tRNAs exit the nucleus. Studies showing that the LOS1 genes of both $S$. cerevisiae and $S$. pombe are nonessential (Hurt et al. 1987; S. Sazer, pers. comm.) provide strong genetic evidence for the existence of an alterna- 
tive tRNA nuclear export pathway(s). Recent biochemical studies indicate the same is likely also the case for vertebrate cells.

In vertebrate cells inhibition of exportin-t via introduction of antibodies specific for exportin-t inhibited tRNA nuclear export $>80 \%$, but did not completely prohibit export (Arts et al. 1998b; Lipowsky et al. 1999). Therefore, exportin-t likely provides the major route for tRNA nuclear export in vertebrates. Nevertheless, two recent studies demonstrate that vertebrate cells also possess an exportin-t-independent tRNA nuclear export pathway. The importin- $\beta$ family member exportin-5 directly binds to either aminoacylated or nonaminoacylated tRNAs in an Ran-GTP-dependent mechanism, providing a secondary tRNA nuclear export pathway for vertebrates. Exportin-5 bound to aminoacylated tRNA also actively depletes the translation elongation factor eEF1 $\alpha$ from the nucleoplasm (Bohnsack et al. 2002; Calado et al. 2002).

Exportin-5 likely also functions to export other RNAs from the nucleus. Studies of nuclear export of adenoviral VA1 RNA (also transcribed by RNA polymerase III) in monkey COS1 cells and Xenopus oocytes identified a minihelix sufficient for nuclear export via Ran-dependent reaction (Gwizdek et al. 2001). Interestingly, excess tRNA could block export of VA1 RNA, but excess minihelix RNAs did not block tRNA export. The data are consistent with the existence of an export pathway responsive to minihelix-containing RNAs that tRNAs are able to access (Gwizdek et al. 2001). Not surprisingly, an unpublished report indicates that the exportin for VA1 RNA is exportin-5 (Gwizdek and Dargemont, pers. comm., cited in Calado et al. 2002).

It is not clear if the yeast Los1p-independent pathway uses the exportin-5 homolog Msn5p. Overexpression of eEF1 $\alpha$ compensates for los 1 null mutations, and mutations of the genes encoding eEF1 $\alpha$ cause a defect in tRNA nuclear export, implicating eEF1 $\alpha$ in an alternative tRNA nuclear export pathway in $S$. cerevisiae (Grosshans et al. 2001). However, as there is no evidence that yeast eEF1 $\alpha$ shuttles between the nucleus and the cytosol, eEF1 $\alpha$ may somehow be involved in tRNA nuclear export via an indirect mechanism (Grosshans et al. 2001). Moreover, although the phenotype of los1 msn5 (encoding the yeast exportin-5 homolog) double mutants has not been reported, deletion of Msn5p does not cause an obvious defect in tRNA nuclear export (Feng and Hopper 2002), indicating that Msn5p (exportin-5) could only provide a minor tRNA nuclear egress pathway for $S$. cerevisiae. It is therefore likely that yeast possess nuclear export pathways that are independent of both Los1p and Msn5p.

Although no yeast importin- $\beta$ family member, other than Los1p, has been identified that is important for tRNA nuclear export, other proteins that function in the Loslp-independent nuclear export pathway have been identified. Mutation of PUS1 causes defects in nuclear tRNA export, and there are synthetic growth defects in los1 pus1 double mutants, perhaps implicating Pus1p in an alternative tRNA export pathway (Simos et al. 1996;
Grosshans et al. 2001). Ccalp, which catalyzes addition of the 3 '-terminal C, C, and A nucleotides to tRNA, and Mes1p, methionyl-tRNA synthetase, are also implicated in an Los1p-independent tRNA nuclear export pathway because Ccalp and Mes1p each are multicopy suppressors of the tRNA nuclear export defect caused by los 1 null mutations, and mutations of the genes encoding these proteins cause nuclear tRNA accumulation (Feng and Hopper 2002). How these proteins function in an Los1p-independent export pathway is unknown. However, S. shibatae CCA-adding enzyme forms stable complexes with CCA-containing tRNAs (Shi et al. 1998), and yeast Ccalp shuttles between the nucleus and cytosol, providing the potential for Ccalp to function directly as an exporter or indirectly as an adapter in an Los1p-independent pathway. Alternatively, pseudouridylation, CCA addition, and aminoacylation could prepare tRNA for interaction with an unidentified exportin (Fig. 2; Feng and Hopper 2002).

In sum, it appears that there are at least two, and perhaps more than two, parallel tRNA nuclear export pathways for both vertebrates and lower eukaryotes. Whether the same exportin-t/Los1p-independent alternative tRNA nuclear export pathways are used in fungi and vertebrates requires further studies.

\section{Coupling of tRNA nuclear export and splicing in \\ S. cerevisiae}

S. cerevisiae mutations in the Ran pathway, LOS1, or any of several genes encoding nucleoporins, which should solely affect tRNA nuclear export, instead also cause defects in pre-tRNA intron removal (Hopper et al. 1978, 1980; Sharma et al. 1996; Simos et al. 1996). The results are in contrast to studies of Xenopus oocytes for which there appears to be no effect of the Ran pathway on pre-tRNA splicing (Lund and Dahlberg 1998). It has been concluded that tRNA nuclear export and splicing are coupled in yeast, but not in vertebrates. However, the effect of the yeast mutations on pre-tRNA splicing can not be absolute because cytosolic pools of spliced tRNAs are essential and some of the genes in question are nonessential. Moreover, mutations of CCA1 or overexpression of Ccalp affect tRNA nuclear export but do not affect pre-tRNA splicing (Sarkar et al. 1999; Grosshans et al. 2000; Feng and Hopper 2002).

What accounts for the partial coupling of pre-tRNA splicing and nuclear export in budding yeast but not in vertebrates? Perhaps yeast Los1p functions directly to couple tRNA splicing to export. In HeLa cells exportin-t location is dynamic, with nucleoplasmic, nuclear rim, and cytosolic locations, accumulating at the nuclear rim when the RanGTPase cycle is disrupted (Kuersten et al. 2002). Although yeast Los $1 p$ also has multiple locations, primarily at nuclear pores, but also throughout the nucleoplasm and in the cytosol, it is not known if its location changes in response to RanGTPase, like its exportin-t counterpart (Shen et al. 1993; Simos et al. 1996). If Los $1 p$ also has dynamic subnuclear distribution, it could have a role in delivering intron-containing tRNAs from 
the nucleoplasm to the NPC-located splicing machinery, providing an explanation as to why mutations of LOS1 or the RanGTPase cycle affect splicing. However, this would not explain why mutant nucleopore proteins affect splicing. Although it is formally possible that increased nuclear tRNA pools resulting from tRNA nuclear export defects would saturate the tRNA splicing machinery, in vitro studies provided no evidence for product inhibition of the splicing endonuclease (Peebles et al. 1979). Another possibility, reminiscent of models for coupling mRNA processing and export (Ishigaki et al. 2001 and references therein), is that tRNA introns could be marked by a tRNA nuclear retention protein that prohibits splicing in the absence of appropriate export machinery, providing a proofreading role for tRNAs whose termini are processed before splicing (Feng and Hopper 2002). Alternatively, as the yeast tRNA splicing enzyme complex has not been verified to be located at the INM (discussed above), an alternative membrane association could result in pre-tRNA splicing only after export.

\section{Import of tRNAs into mitochondria}

Numerous fungi, protists, plants, and animals import tRNA from the cytosol into mitochondria. Mitochondrial genomes vary in the number of encoded tRNAs, ranging from zero, as in some trypanosomatids, to the full complement used in mitochondria protein synthesis in organisms like S. cerevisiae and humans. Thus, for some organisms, mitochondria tRNA import from the cytosol is essential. Mitochondrial genomes use a nonstandard genetic code with, for example, mitochondria tRNAs inserting amino acids in response to stop codons. The corresponding imported tRNAs must be prevented from participating in protein synthesis while in the cytosol. Indeed, both tRNA editing and tRNA modification events occur inside the mitochondria that activate some of the imported tRNAs (for review, see Schneider and Marechal-Drouard 2000; also, see discussions above).

Import of tRNAs into mitochondria has been studied in the most detail for S. cerevisiae, and for several different trypanosomatids. S. cerevisiae imports $3 \%-5 \%$ of the total cytosolic pool of a single tRNA, tRNA ${ }_{\mathrm{CuU}}{ }^{\text {Lys, }}$, into mitochondria. This tRNA is first aminoacylated by cytosolic lysyl-tRNA synthetase. In general, mutant tRNAs that cannot be aminoacylated also are not imported into mitochondria, showing that aminoacylation is required for import. However, it appears that import does not require the presence of an amino acid on tRNA per se because a few particular mutant tRNAs that are unable to be aminoacylated are still imported. Rather, the data support the idea that amino acid addition in the cytosol alters tRNA conformation, allowing subsequent mitochondria import steps (Entelis et al. 1998). Aminoacylated tRNA ${ }_{\mathrm{CUU}}{ }^{\text {Lys }}$ interacts in the cytosol with the precursor to mitochondria lysyl-tRNA synthetase (preMSK), followed by mitochondria import. The import requirements are similar to those for mitochondria-imported proteins (summarized in Entelis et al. 1998). As imported proteins are thought to be unfolded on the cy- tosolic face of mitochondria prior to import, it is unclear whether tRNA ${ }_{\mathrm{CUU}}{ }^{\text {Lys }}$-pre-MSK is imported as a complex or, instead, whether interaction with pre-MSK alters tRNA ${ }_{\mathrm{CUU}}{ }^{\text {ys }}$, making it import-competent (Entelis et al. 1998; for review, see Entelis et al. 2001).

Although import of tRNA ${ }_{\mathrm{CuU}}{ }^{\text {Lys }}$ into yeast mitochondria is not essential for mitochondrial protein synthesis, and, in fact, tRNA ${ }_{\mathrm{CUU}}{ }^{\text {Lys }}$ appears not to be aminoacylated by mitochondrial lysyl-tRNA synthetase (Entelis et al. 2001), this imported tRNA can function in translation. Recent studies changing the identity elements of tRNA $_{\text {CuU }}{ }^{\text {Lys }}$ to tRNA ${ }^{\text {Met }}$ or to a tRNA ${ }^{\text {Ala }}$, able to basepair with nonsense codons, resulted in aminoacylation of the mutant tRNAs by methionyl-tRNA or alanyltRNA synthetase, respectively. In vitro import studies and in vivo nonsense suppression assays showed the imported tRNAs are active in mitochondria protein synthesis (Kolesnikova et al. 2000). Moreover, human mitochondria, not known to import tRNA, were able to import yeast tRNA $_{\mathrm{CUU}}{ }^{\text {Lys }}$ in vitro, provided that human cytosolic extracts contained the yeast pre-MSK (Kolesnikova et al. 2000). The combined studies demonstrate that for S. cerevisiae: (1) mitochondrial tRNA import requires trans-acting proteins like the cytosolic and precursor mitochondrial tRNA synthetases; (2) identity of the amino acid on the tRNA is unimportant for mitochondria import; (3) imported tRNAs can participate in protein synthesis; and (4) the import machinery is similar from yeast to humans.

The mechanism of mitochondrial tRNA import for trypanosomatids likely differs from that of budding yeast. Trypanosomatid mitochondrial tRNA import appears not to require cytosolic proteins, but, rather, only proteinaceous receptors on the mitochondrial surface; however, it is difficult to completely rule out cytosolic contamination in the in vitro import systems (Schneider and Marechal-Drouard 2000). The nature of imported tRNA is controversial and may differ between species. Some studies conclude that only pre-tRNAs with $5^{\prime}$ extensions are imported, whereas other studies show the sequence of the $5^{\prime}$ extension to be unimportant, supporting the model that only mature tRNAs are imported (Yermovsky-Kammerer and Hajduk 1999; Tan et al. 2002). If, indeed, pre-tRNAs are imported in vivo, these tRNAs would have to somehow escape the processing and proofreading activities located in the nucleus and be exported to the cytosol with intact $5^{\prime}$ and $3^{\prime}$ extensions.

For both S. cerevisiae and trypanosomatids there have been numerous studies to map tRNA determinants important to their mitochondrial import. Studies of the yeast tRNA ${ }_{\mathrm{CUU}}{ }^{\text {Lys }}$ are complicated because tRNA determinants affect interaction with the cytosolic and preMSK. Recently, the SELEX procedure has been used to characterize Leishmania tRNA motifs important for mitochondrial import. The studies uncovered two types of tRNA-like motifs. The former were efficiently imported, but the latter, remarkably, were imported efficiently only in the presence of the former. The investigators propose that tRNA-tRNA interactions regulate the pool of tRNAs imported into mitochondria (Bhattacharyya et al. 2002). 


\section{Conclusions}

The excitement in tRNA biology resulting from the explosion of newly identified tRNA-processing genes, the investigation of tRNA processing in a wide array of organisms, and from increasingly sophisticated use of powerful cell biological and genetic tools to track tRNAs movement, is just beginning. It is clear that the next few years will bring valuable insights into the function of many genes involved in tRNA biogenesis, new revelations about the intricacies of tRNA-processing biochemistry, more connections between tRNA-processing machinery and other cellular functions, and greater understanding of the movement of tRNA in the cell, and factors influencing its movement. Understanding tRNA biology has become cool again, and it seems likely that it will remain so during the next decade.

\section{Acknowledgments}

Work in the authors' laboratories is funded by grants from the National Institution of Health and the National Science Foundation. We thank D. Görlich, U. Kutay, S. Sazer, and D. Tollervey for communicating results prior to publication; E. Lund for insightful comments; members of the A.K.H. and E.M.P. laboratories for comments on the manuscript; and F. Xing for help with the figures. We are especially grateful to E. Grayhack for scientific and editorial insights.

\section{References}

Alexandrov, A.V., Martzen, M.R., and Phizicky, E.M. 2002. Two proteins that form a complex are required for 7-methylguanosine modification of yeast tRNA. RNA 8: 1253-1266.

Alfonzo, J.D., Blanc, V., Estevez, A.M., Rubio, M.A., and Simpson, L. 1999. C to U editing of the anticodon of imported mitochondrial tRNA ${ }^{\text {Trp }}$ allows decoding of the UGA stop codon in Leishmania tarentolae. EMBO J. 18: 7056-7062.

Anderson, J., Phan, L., Cuesta, R., Carlson, B.A., Pak, M., Asano, K., Björk, G.R., Tamame, M., and Hinnebusch, A.G. 1998. The essential Gcd10p-Gcd14p nuclear complex is required for 1-methyladenosine modification and maturation of initiator methionyl-tRNA. Genes \& Dev. 12: 3650-3662.

Anderson, J., Phan, L., and Hinnebusch, A.G. 2000. The Gcd10p/Gcd14p complex is the essential two-subunit tRNA(1-methyladenosine) methyltransferase of Saccharomyces cerevisiae. Proc. Natl. Acad. Sci. 97: 5173-5178.

Ansmant, I., Motorin, Y., Massenet, S., Grosjean, H., and Branlant, C. 2001. Identification and characterization of the tRNA: $\Psi$ 31-synthase (Pus6p) of Saccharomyces cerevisiae. J. Biol. Chem. 276: 34934-34940.

Antes, T., Costandy, H., Mahendran, R., Spottswood, M., and Miller, D. 1998. Insertional editing of mitochondrial tRNAs of Physarum polycephalum and Didymium nigripes. Mol. Cell. Biol. 18: 7521-7527.

Arts, G.J., Fornerod, M., and Mattaj, I.W. 1998a. Identification of a nuclear export receptor for tRNA. Curr. Biol. 8: 305-314.

Arts, G.J., Kuersten, S., Romby, P., Ehresmann, B., and Mattaj, I.W. 1998b. The role of exportin-t in selective nuclear export of mature tRNAs. EMBO J. 17: 7430-7441.
Åström, S.U. and Byström, A.S. 1994. Rit1, a tRNA backbonemodifying enzyme that mediates initiator and elongator tRNA discrimination. Cell 79: 535-546.

Åström, S.U., Nordlund, M.E., Erickson, F.L., Hannig, E.M., and Byström, A.S. 1999. Genetic interactions between a null allele of the RIT1 gene encoding an initiator tRNA-specific modification enzyme and genes encoding translation factors in Saccharomyces cerevisiae. Mol. Gen. Genet. 261: 967976.

Azad, A.K., Stanford, D.R., Sarkar, S., and Hopper, A.K. 2001. Role of nuclear pools of aminoacyl-tRNA synthetases in tRNA nuclear export. Mol. Biol. Cell 12: 1381-1392.

Becker, H.F., Motorin, Y., Planta, R.J., and Grosjean, H. 1997. The yeast gene YNL292w encodes a pseudouridine synthase (Pus4) catalyzing the formation of psi55 in both mitochondrial and cytoplasmic tRNAs. Nucleic Acids Res. 25: 44934499.

Benko, A.L., Vaduva, G., Martin, N.C., and Hopper, A.K. 2000. Competition between a sterol biosynthetic enzyme and tRNA modification in addition to changes in the protein synthesis machinery causes altered nonsense suppression. Proc. Natl. Acad. Sci. 97: 61-66.

Bertrand, E., Houser-Scott, F., Kendall, A., Singer, R.H., and Engelke, D.R. 1998. Nucleolar localization of early tRNA processing. Genes \& Dev. 12: 2463-2468.

Bhattacharyya, S.N., Chatterjee, S., and Adhya, S. 2002. Mitochondrial RNA import in Leishmania tropica: Aptamers homologous to multiple tRNA domains that interact cooperatively or antagonistically at the inner membrane. Mol. Cell. Biol. 22: 4372-4382.

Binder, S., Marchfelder, A., and Brennicke, A. 1994. RNA editing of tRNA ${ }^{\text {Phe }}$ and tRNA ${ }^{\text {Cys }}$ in mitochondria of Oenothera berteriana is initiated in precursor molecules. Mol. Gen. Genet. 244: 67-74.

Bishop, A.C., Xu, J., Johnson, R.C., Schimmel, P., and de CrecyLagard, V. 2002. Identification of the tRNA-dihydrouridine synthase family. J. Biol. Chem. 277: 25090-25095.

Björk, G.R. 1995. Biosynthesis and function of modified nucleosides. In tRNA: Structure, biosynthesis and function (eds. D. Söll and U.L. RajBhandary), pp. 165-205. ASM Press, Washington, D.C.

Björk, G.R., Jacobsson, K., Nilsson, K., Johansson, M.J., Byström, A.S., and Persson, O.P. 2001. A primordial tRNA modification required for the evolution of life? EMBO $J$. 20: 231-239.

Boguta, M., Hunter, L.A., Shen, W.C., Gillman, E.C., Martin, N.C., and Hopper, A.K. 1994. Subcellular locations of MOD5 proteins: Mapping of sequences sufficient for targeting to mitochondria and demonstration that mitochondrial and nuclear isoforms commingle in the cytosol. Mol. Cell. Biol. 14: 2298-2306.

Bohnsack, M.T., Regener, K., Schwappach, B., Saffrich, R., Paraskeva, E., Hartmann, E., and Görlich, D. 2002. Exp5 exports eEF1A via tRNA from nuclei and synergizes with other transport pathways to confine translation to the cytoplasm. EMBO J. 21: 6205-6215.

Brusca, E.M., True, H.L., and Celander, D.W. 2001. Novel RNAbinding properties of Pop3p support a role for eukaryotic RNase P protein subunits in substrate recognition. J. Biol. Chem. 276: 42543-42548.

Burger, G., Plante, I., Lonergan, K.M., and Gray, M.W. 1995. The mitochondrial DNA of the amoeboid protozoon, Acanthamoeba castellanii: Complete sequence, gene content and genome organization. J. Mol. Biol. 245: 522-537.

Cai, T., Aulds, J., Gill, T., Cerio, M., and Schmitt, M.E. 2002. The Saccharomyces cerevisiae RNase mitochondrial RNA 
processing is critical for cell cycle progression at the end of mitosis. Genetics 161: 1029-1042.

Calado, A., Treichel, N., Muller, E.C., Otto, A., and Kutay, U. 2002. Exportin-5-mediated nuclear export of eukaryotic elongation factor 1A and tRNA. EMBO T. 21: 6216-6224.

Calfon, M., Zeng, H., Urano, F., Till, J.H., Hubbard, S.R., Harding, H.P., Clark, S.G., and Ron, D. 2002. IRE1 couples endoplasmic reticulum load to secretory capacity by processing the XBP-1 mRNA. Nature 415: 92-96.

Calvo, O., Cuesta, R., Anderson, J., Gutierrez, N., Garcia-Barrio, M.T., Hinnebusch, A.G., and Tamame, M. 1999. GCD14p, a repressor of GCN4 translation, cooperates with Gcd10p and Lhplp in the maturation of initiator methionyl-tRNA in Saccharomyces cerevisiae. Mol. Cell. Biol. 19: 4167-4181.

Carpousis, A.J., Vanzo, N.F., and Raynal, L.C. 1999. mRNA degradation. A tale of poly(A) and multiprotein machines. Trends Genet. 15: 24-28.

Cavaillé, J., Chetouani, F., and Bachellerie, J. P. 1999. The yeast Saccharomyces cerevisiae YDL112w ORF encodes the putative 2 '-O-ribose methyltransferase catalyzing the formation of Gm18 in tRNAs. RNA 5: 66-81.

Chamberlain, J.R., Lee, Y., Lane, W.S., and Engelke, D.R. 1998. Purification and characterization of the nuclear RNase P holoenzyme complex reveals extensive subunit overlap with RNase MRP. Genes \& Dev. 12: 1678-1690.

Clark, M.W. and Abelson, J. 1987. The subnuclear localization of tRNA ligase in yeast. J. Cell Biol. 105: 1515-1526.

Culver, G.M., McCraith, S.M., Zillmann, M., Kierzek, R., Michaud, N., LaReau, R.D., Turner, D.H., and Phizicky, E.M. 1993. An NAD derivative produced during transfer RNA splicing: ADP-ribose $1^{\prime \prime}-2^{\prime \prime}$ cyclic phosphate. Science 261: 206-208.

Culver, G.M., McCraith, S.M., Consaul, S.A., Stanford, D.R., and Phizicky, E.M. 1997. A 2'-phosphotransferase implicated in tRNA splicing is essential in Saccharomyces cerevisiae. J. Biol. Chem. 272: 13203-13210.

Dahlberg, J.E., Lund, E., and Goodwin, E. 2003. Translation in the nucleus: What's the evidence? RNA (in press).

Del Campo, M., Kaya, Y., and Ofengand, J. 2001. Identification and site of action of the remaining four putative pseudouridine synthases in Escherichia coli. RNA 7: 1603-1615.

Deutscher, M.P. 1972. Reactions at the $3^{\prime}$ terminus of transfer ribonucleic acid. 3. Catalytic properties of two purified rabbit liver transfer ribonucleic acid nucleotidyl transferases. $J$. Biol. Chem. 247: 459-468.

Dihanich, M.E., Najarian, D., Clark, R., Gillman, E.C., Martin, N.C., and Hopper, A.K. 1987. Isolation and characterization of $M O D 5$, a gene required for isopentenylation of cytoplasmic and mitochondrial tRNAs of Saccharomyces cerevisiae. Mol. Cell. Biol. 7: 177-184; Erratum 7: 2035.

d'Orval, B.C., Bortolin, M.L., Gaspin, C., and Bachellerie, J.P. 2001. Box C/D RNA guides for the ribose methylation of archaeal tRNAs. The tRNA ${ }^{\operatorname{Trp}}$ intron guides the formation of two ribose-methylated nucleosides in the mature tRNA $^{\text {Trp }}$. Nucleic Acids Res. 29: 4518-4529.

Ellis, S.R., Morales, M.J., Li, J.M., Hopper, A.K., and Martin, N.C. 1986. Isolation and characterization of the TRM1 locus, a gene essential for the $N^{2}, N^{2}$-dimethylguanosine modification of both mitochondrial and cytoplasmic tRNA in Saccharomyces cerevisiae. J. Biol. Chem. 261: 9703-9709.

Entelis, N.S., Kieffer, S., Kolesnikova, O.A., Martin, R.P., and Tarassov, I.A. 1998. Structural requirements of tRNA ${ }^{\text {Lys }}$ for its import into yeast mitochondria. Proc. Natl. Acad. Sci. 95: 2838-2843.

Entelis, N.S., Kolesnikova, O.A., Martin, R.P., and Tarassov, I.A. 2001. RNA delivery into mitochondria. Adv. Drug De- liv. Rev. 49: 199-215.

Etcheverry, T., Colby, D., and Guthrie, C. 1979. A precursor to a minor species of yeast tRNA ${ }^{\mathrm{Ser}}$ contains an intervening sequence. Cell 18: 11-26.

Fabbri, S., Fruscoloni, P., Bufardeci, E., Di Nicola Negri, E., Baldi, M.I., Attardi, D.G., Mattoccia, E., and Tocchini-Valentini, G.P. 1998. Conservation of substrate recognition mechanisms by tRNA splicing endonucleases. Science 280: $284-286$.

Feng, W. and Hopper, A.K. 2002. A Los1p-independent pathway for nuclear export of intronless tRNAs in Saccharomyces cerevisiae. Proc. Natl. Acad. Sci. 99: 5412-5417.

Filipowicz, W. and Shatkin, A.J. 1983. Origin of splice junction phosphate in tRNAs processed by HeLa cell extract. Cell 32: $547-557$.

Galani, K., Grosshans, H., Deinert, K., Hurt, E.C., and Simos, G. 2001. The intracellular location of two aminoacyl-tRNA synthetases depends on complex formation with Arclp. EMBO T. 20: 6889-6898.

Garcia-Barrio, M.T., Naranda, T., Vazquez de Aldana, C.R., Cuesta, R., Hinnebusch, A.G., Hershey, J.W., and Tamame, M. 1995. GCD10, a translational repressor of GCN4, is the RNA-binding subunit of eukaryotic translation initiation factor-3. Genes \& Dev. 9: 1781-1796.

Gerber, A.P. and Keller, W. 1999. An adenosine deaminase that generates inosine at the wobble position of tRNAs. Science 286: $1146-1149$

Gerber, A., Grosjean, H., Melcher, T., and Keller, W. 1998. Tad1p, a yeast tRNA-specific adenosine deaminase, is related to the mammalian pre-mRNA editing enzymes ADAR1 and ADAR2. EMBO I. 17: 4780-4789.

Gomes, I. and Gupta, R. 1997. RNA splicing ligase activity in the archaeon Haloferax volcanii. Biochem. Biophys. Res. Comm. 237: 588-594.

Gonzalez, T.N., Sidrauski, C., Dorfler, S., and Walter, P. 1999. Mechanism of non-spliceosomal mRNA splicing in the unfolded protein response pathway. EMBO J. 18: 3119-3132.

Görlich, D. and Kutay, U. 1999. Transport between the cell nucleus and the cytoplasm. Annu. Rev. Cell Dev. Biol. 15: 607-660.

Grayhack, E.J. and Phizicky, E.M. 2001. Genomic analysis of biochemical function. Curr. Opin. Chem. Biol. 5: 34-39.

Grosjean, H., Szweykowska-Kulinska, Z., Motorin, Y., Fasiolo, F., and Simos, G. 1997. Intron-dependent enzymatic formation of modified nucleosides in eukaryotic tRNAs: A review. Biochimie 79: 293-302.

Grosshans, H., Hurt, E., and Simos, G. 2000. An aminoacylation-dependent nuclear tRNA export pathway in yeast. Genes \& Dev. 14: 830-840.

Grosshans, H., Lecointe, F., Grosjean, H., Hurt, E., and Simos, G. 2001. Pus1p-dependent tRNA pseudouridinylation becomes essential when tRNA biogenesis is compromised in yeast. J. Biol. Chem. 276: 46333-46339.

Guerrier-Takada, C. and Altman, S. 1984. Catalytic activity of an RNA molecule prepared by transcription in vitro. Science 223: $285-286$.

Gustafsson, C., Reid, R., Greene, P.J., and Santi, D.V. 1996. Identification of new RNA modifying enzymes by iterative genome search using known modifying enzymes as probes. Nucleic Acids Res. 24: 3756-3762.

Gutgsell, N., Englund, N., Niu, L., Kaya, Y., Lane, B.G., and Ofengand, J. 2000. Deletion of the Escherichia coli pseudouridine synthase gene truB blocks formation of pseudouridine 55 in tRNA in vivo, does not affect exponential growth, but confers a strong selective disadvantage in competition with wild-type cells. RNA 6: 1870-1881. 
Gwizdek, C., Bertrand, E., Dargemont, C., Lefebvre, J.C., Blanchard, J.M., Singer, R.H., and Doglio, A. 2001. Terminal minihelix, a novel RNA motif that directs polymerase III transcripts to the cell cytoplasm. Terminal minihelix and RNA export. J. Biol. Chem. 276: 25910-25918.

Hellmuth, K., Lau, D.M., Bischoff, F.R., Kunzler, M., Hurt, E., and Simos, G. 1998. Yeast Los1p has properties of an exportin-like nucleocytoplasmic transport factor for tRNA. Mol. Cell. Biol. 18: 6374-6386.

Hellmuth, K., Grosjean, H., Motorin, Y., Deinert, K., Hurt, E., and Simos, G. 2000. Cloning and characterization of the Schizosaccharomyces pombe tRNA:pseudouridine synthase Pus1p. Nucleic Acids Res. 28: 4604-4610.

Ho, C.K., Rauhut, R., Vijayraghavan, U., and Abelson, J. 1990. Accumulation of pre-tRNA splicing ' $2 / 3$ ' intermediates in a Saccharomyces cerevisiae mutant. EMBO J. 9: 1245-1252.

Hopper, A.K., Banks, F., and Evangelides, V. 1978. A yeast mutant which accumulates precursor tRNAs. Cell 14: 211-219.

Hopper, A.K., Schultz, L.D., and Shapiro, R.A. 1980. Processing of intervening sequences: A new yeast mutant which fails to excise intervening sequences from precursor tRNAs. Cell 19: 741-751.

Hopper, A.K., Furukawa, A.H., Pham, H.D., and Martin, N.C. 1982. Defects in modification of cytoplasmic and mitochondrial transfer RNAs are caused by single nuclear mutations. Cell 28: 543-550.

Hou, Y.M. 2000. Unusual synthesis by the Escherichia coli CCA-adding enzyme. RNA 6: 1031-1043.

Houser-Scott, F., Xiao, S., Millikin, C.E., Zengel, J.M., Lindahl, L., and Engelke, D.R. 2002. Interactions among the protein and RNA subunits of Saccharomyces cerevisiae nuclear RNase P. Proc. Natl. Acad. Sci. 99: 2684-2689.

Hurt, D.J., Wang, S.S., Lin, Y.H., and Hopper, A.K. 1987. Cloning and characterization of LOS1, a Saccharomyces cerevisiae gene that affects tRNA splicing. Mol. Cell. Biol. 7: 1208-1216.

Intine, R.V., Dundr, M., Misteli, T., and Maraia, R.J. 2002. Aberrant nuclear trafficking of La protein leads to disordered processing of associated precursor tRNAs. Mol. Cell 9: 11131123.

Ishigaki, Y., Li, X., Serin, G., and Maquat, L.E. 2001. Evidence for a pioneer round of mRNA translation: mRNAs subject to nonsense-mediated decay in mammalian cells are bound by CBP80 and CBP20. Cell 106: 607-617.

Janke, A. and Paabo, S. 1993. Editing of a tRNA anticodon in marsupial mitochondria changes its codon recognition. Nucleic Acids Res. 21: 1523-1525.

Jarrous, N. 2002. Human ribonuclease P: Subunits, function, and intranuclear localization. RNA 8: 1-7.

Johansson, M.J. and Byström, A.S. 2002. Dual function of the tRNA(m $\left.{ }^{5} \mathrm{U} 54\right)$ methyltransferase in tRNA maturation. RNA 8: 324-335.

Johnson, P.F. and Abelson, J. 1983. The yeast tRNA ${ }^{\text {Tyr }}$ gene intron is essential for correct modification of its tRNA product. Nature 302: 681-687.

Kleman-Leyer, K., Armbruster, D.W., and Daniels, C.J. 1997. Properties of $H$. volcanii tRNA intron endonuclease reveal a relationship between the archaeal and eucaryal tRNA intron processing systems. Cell 89: 839-847.

Ko, Y.G., Kang, Y.S., Kim, E.K., Park, S.G., and Kim, S. 2000. Nucleolar localization of human methionyl-tRNA synthetase and its role in ribosomal RNA synthesis. J. Cell Biol. 149: $567-574$.

Kolesnikova, O.A., Entelis, N.S., Mireau, H., Fox, T.D., Martin, R.P., and Tarassov, I.A. 2000. Suppression of mutations in mitochondrial DNA by tRNAs imported from the cyto- plasm. Science 289: 1931-1933.

Konarska, M., Filipowicz, W., and Gross, H.J. 1982. RNA ligation via $2^{\prime}$-phosphomonoester, $3^{\prime} 5^{\prime}$-phosphodiester linkage: Requirement of $2^{\prime}, 3^{\prime}$-cyclic phosphate termini and involvement of a 5'-hydroxyl polynucleotide kinase Proc. Natl. Acad. Sci. 79: 1474-1478.

Koonin, E.V. 1996. Pseudouridine synthases: Four families of enzymes containing a putative uridine-binding motif also conserved in dUTPases and dCTP deaminases. Nucleic Acids Res. 24: 2411-2415.

Kuersten, S., Arts, G.J., Walther, T.C., Englmeier, L., and Mattaj, I.W. 2002. Steady-state nuclear localization of exportin-t involves RanGTP binding and two distinct nuclear pore complex interaction domains. Mol. Cell. Biol. 22: 5708 5720.

Kufel, J. and Tollervey, D. 2003. 3'-processing of yeast tRNA ${ }^{\operatorname{Tr}}$ precedes $5^{\prime}$-processing. $R N A$ (in press).

Kutay, U., Lipowsky, G., Izaurralde, E., Bischoff, F.R., Schwarzmaier, P., Hartmann, E., and Görlich, D. 1998. Identification of a tRNA-specific nuclear export receptor. Mol. Cell 1: 359-369.

Kuwabara, T., Warashina, M., Sano, M., Tang, H., Wong-Staal, F., Munekata, E., and Taira, K. 2001. Recognition of engineered tRNAs with an extended 3 ' end by exportin-t (Xpo-t) and transport of tRNA-attached ribozymes to the cytoplasm in somatic cells. Biomacromolecules 2: 1229-1242.

Laski, F.A., Fire, A.Z., RajBhandary, U.L., and Sharp, P.A. 1983. Characterization of tRNA precursor splicing in mammalian extracts. J. Biol. Chem. 258: 11974-11980.

Laten, H., Gorman, J., and Bock, R.M. 1978. Isopentenyladenosine deficient tRNA from an antisuppressor mutant of Saccharomyces cerevisiae. Nucleic Acids Res. 5: 43294342.

Lavrov, D.V., Brown, W.M., and Boore, J.L. 2000. A novel type of RNA editing occurs in the mitochondrial tRNAs of the centipede Lithobius forficatus. Proc. Nat1. Acad. Sci. 97: 1373813742.

Lecointe, F., Simos, G., Sauer, A., Hurt, E.C., Motorin, Y., and Grosjean, H. 1998. Characterization of yeast protein Deg1 as pseudouridine synthase (Pus3) catalyzing the formation of $\Psi$ 38 and $\Psi 39$ in tRNA anticodon loop. J. Biol. Chem. 273: $1316-1323$.

Lemieux, J., Lakowski, B., Webb, A., Meng, Y., Ubach, A., Bussiere, F., Barnes, T., and Hekimi, S. 2001. Regulation of physiological rates in Caenorhabditis elegans by a tRNAmodifying enzyme in the mitochondria. Genetics 159: 147157.

Li, F., Wang, J., and Steitz, T.A. 2000. Sulfolobus shibatae CCAadding enzyme forms a tetramer upon binding two tRNA molecules: A scrunching-shuttling model of CCA specificity. J. Mol. Biol. 304: 483-492.

Li, H., Trotta, C.R., and Abelson, J. 1998a. Crystal structure and evolution of a transfer RNA splicing enzyme. Science 280: 279-284.

Li, J.M., Hopper, A.K., and Martin, N.C. 1989. $N^{2}, N^{2}$-dimethylguanosine-specific tRNA methyltransferase contains both nuclear and mitochondrial targeting signals in Saccharomyces cerevisiae. J. Cell Biol. 109: 1411-1419.

Li, Z. and Deutscher, M.P. 1994. The role of individual exoribonucleases in processing at the $3^{\prime}$ end of Escherichia coli tRNA precursors. J. Biol. Chem. 269: 6064-6071.

- 1996. Maturation pathways for E. coli tRNA precursors: A random multienzyme process in vivo. Cell 86: 503-512.

. 2002. RNase E plays an essential role in the maturation of Escherichia coli tRNA precursors. RNA 8: 97-109.

Li, Z., Pandit, S., and Deutscher, M.P. 1998b. Polyadenylation of 
stable RNA precursors in vivo. Proc. Natl. Acad. Sci. 95: 12158-12162.

Li, Z., Reimers, S., Pandit, S., and Deutscher, M.P. 2002. RNA quality control: Degradation of defective transfer RNA. EMBO J. 21: 1132-1138.

Lipowsky, G., Bischoff, F.R., Izaurralde, E., Kutay, U., Schafer, S., Gross, H.J., Beier, H., and Görlich, D. 1999. Coordination of tRNA nuclear export with processing of tRNA. RNA 5: 539-549.

Lonergan, K.M. and Gray, M.W. 1993. Editing of transfer RNAs in Acanthamoeba castellanii mitochondria. Science 259: 812-816.

Lund, E. and Dahlberg, J.E. 1998. Proofreading and aminoacylation of tRNAs before export from the nucleus. Science 282: 2082-2085.

Lykke-Andersen, J. and Garrett, R.A. 1997. RNA-protein interactions of an archaeal homotetrameric splicing endoribonuclease with an exceptional evolutionary history. EMBO J. 16: 6290-6300.

Maniatis, T. and Reed, R. 2002. An extensive network of coupling among gene expression machines. Nature 416: 499506.

Maraia, R.J. and Intine, R.V. 2002. La protein and its associated small nuclear and nucleolar precursor RNAs. Gene Expr. 10: 41-57.

Marchfelder, A., Brennicke, A., and Binder, S. 1996. RNA editing is required for efficient excision of tRNA ${ }^{\text {Phe }}$ from precursors in plant mitochondria. J. Biol. Chem. 271: 1898-1903.

Marechal-Drouard, L., Ramamonjisoa, D., Cosset, A., Weil, J.H., and Dietrich, A. 1993. Editing corrects mispairing in the acceptor stem of bean and potato mitochondrial phenylalanine transfer RNAs. Nucleic Acids Res. 21: 4909-4914.

Marechal-Drouard, L., Cosset, A., Remacle, C., Ramamonjisoa, D., and Dietrich, A. 1996a. A single editing event is a prerequisite for efficient processing of potato mitochondrial phenylalanine tRNA. Mol. Cell. Biol. 16: 3504-3510.

Marechal-Drouard, L., Kumar, R., Remacle, C., and Small, I. 1996b. RNA editing of larch mitochondrial tRNA ${ }^{\text {His }}$ precursors is a prerequisite for processing. Nucleic Acids Res. 24: $3229-3234$.

Martzen, M.R., McCraith, S.M., Spinelli, S.L., Torres, F.M., Fields, S., Grayhack, E.J., and Phizicky, E.M. 1999. A biochemical genomics approach for identifying genes by the activity of their products. Science 286: 1153-1155.

Massenet, S., Motorin, Y., Lafontaine, D.L., Hurt, E.C. Grosjean, H., and Branlant, C. 1999. Pseudouridine mapping in the Saccharomyces cerevisiae spliceosomal U small nuclear RNAs (snRNAs) reveals that pseudouridine synthase pus1p exhibits a dual substrate specificity for U2 snRNA and tRNA. Mol. Cell. Biol. 19: 2142-2154.

Melton, D.A., De Robertis, E.M., and Cortese, R. 1980. Order and intracellular location of the events involved in the maturation of a spliced tRNA. Nature 284: 143-148.

Motorin, Y. and Grosjean, H. 1999. Multisite-specific tRNA: ${ }^{5} \mathrm{C}$-methyltransferase (Trm4) in yeast Saccharomyces cerevisiae: Identification of the gene and substrate specificity of the enzyme. RNA 5: 1105-1118.

Motorin, Y., Bec, G., Tewari, R., and Grosjean, H. 1997. Transfer RNA recognition by the Escherichia coli $\Delta^{2}$-isopentenyl-pyrophosphate:tRNA $\Delta^{2}$-isopentenyl transferase: Dependence on the anticodon arm structure. RNA 3: 721-733.

Motorin, Y., Keith, G., Simon, C., Foiret, D., Simos, G., Hurt, E., and Grosjean, H. 1998. The yeast tRNA:pseudouridine synthase Puslp displays a multisite substrate specificity. RNA 4: $856-869$.

Nathanson, L. and Deutscher, M.P. 2000. Active aminoacyl-
tRNA synthetases are present in nuclei as a high molecular weight multienzyme complex. J. Biol. Chem. 275: 3155931562.

Nishikura, K. and De Robertis, E.M. 1981. RNA processing in microinjected Xenopus oocytes. Sequential addition of base modifications in the spliced transfer RNA. J. Mol. Biol. 145: 405-420.

Niwa, M., Sidrauski, C., Kaufman, R.J., and Walter, P. 1999. A role for presenilin-1 in nuclear accumulation of Ire1 fragments and induction of the mammalian unfolded protein response. Cell 99: 691-702.

Nordlund, M.E., Johansson, J.O., von Pawel-Rammingen, U., and Byström, A.S. 2000. Identification of the TRM2 gene encoding the tRNA $\left(\mathrm{m}^{5} \mathrm{U} 54\right)$ methyltransferase of Saccharomyces cerevisiae. RNA 6: 844-860.

O'Connor, J.P. and Peebles, C.L. 1991. In vivo pre-tRNA processing in Saccharomyces cerevisiae. Mol. Cell. Biol. 11: 425-439.

O'Hara, E.B., Chekanova, J.A., Ingle, C.A., Kushner, Z.R., Peters, E., and Kushner, S.R. 1995. Polyadenylylation helps regulate mRNA decay in Escherichia coli. Proc. Nat1. Acad. Sci. 92: 1807-1811.

Ow, M.C. and Kushner, S.R. 2002. Initiation of tRNA maturation by RNase E is essential for cell viability in E. coli. Genes \& Dev. 16: 1102-1115.

Papadimitriou, A. and Gross, H.J. 1996. Pre-tRNA 3'-processing in Saccharomyces cerevisiae. Purification and characterization of exo- and endoribonucleases. Eur. J. Biochem. 242: 747-759.

Peebles, C.L., Ogden, R.C., Knapp, G., and Abelson, J. 1979. Splicing of yeast tRNA precursors: A two-stage reaction. Cell 18: 27-35.

Peebles, C.L., Gegenheimer, P., and Abelson, J. 1983. Precise excision of intervening sequences from precursor tRNAs by a membrane-associated yeast endonuclease. Cell 32: $525-536$.

Persson, B.C., Gustafsson, C., Berg, D.E., and Bjork, G.R. 1992. The gene for a tRNA modifying enzyme, m5U54-methyltransferase, is essential for viability in Escherichia coli. Proc. Natl. Acad. Sci. 89: 3995-3998.

Phillips, J.H. and Kjellin-Stråby, K. 1967. Studies on microbial ribonucleic acid. IV. Two mutants of Saccharomyces cerevisiae lacking $\mathrm{N}$-2-dimethylguanine in soluble ribonucleic acid. J. Mol. Biol. 26: 509-518.

Phizicky, E.M., Consaul, S.A., Nehrke, K.W., and Abelson, J. 1992. Yeast tRNA ligase mutants are nonviable and accumulate tRNA splicing intermediates. J. Biol. Chem. 267: 4577-4582.

Pick, L. and Hurwitz, J. 1986. Purification of wheat germ RNA ligase. I. Characterization of a ligase-associated 5'-hydroxyl polynucleotide kinase activity. J. Biol. Chem. 261: 66846693.

Pintard, L., Lecointe, F., Bujnicki, J.M., Bonnerot, C., Grosjean, H., and Lapeyre, B. 2002. Trm7p catalyses the formation of two 2'-O-methylriboses in yeast tRNA anticodon loop. EMBO J. 21: 1811-1820.

Price, D.H. and Gray, M.W. 1999. A novel nucleotide incorporation activity implicated in the editing of mitochondrial transfer RNAs in Acanthamoeba castellanii. RNA 5: 302317.

Qiu, H., Hu, C., Anderson, J., Bjork, G.R., Sarkar, S., Hopper, A.K., and Hinnebusch, A.G. 2000. Defects in tRNA processing and nuclear export induce GCN4 translation independently of phosphorylation of the $\alpha$ subunit of eukaryotic translation initiation factor 2. Mol. Cell. Biol. 20: $2505-2516$. 
Raychaudhuri, S., Niu, L., Conrad, J., Lane, B.G., and Ofengand, J. 1999. Functional effect of deletion and mutation of the Escherichia coli ribosomal RNA and tRNA pseudouridine synthase RluA. J. Biol. Chem. 274: 18880-18886.

Rose, A.M., Belford, H.G., Shen, W.C., Greer, C.L., Hopper, A.K., and Martin, N.C. 1995. Location of $N^{2}, N^{2}$-dimethylguanosine-specific tRNA methyltransferase. Biochimie 77: 45-53.

Ruegsegger, U., Leber, J.H., and Walter, P. 2001. Block of HAC1 mRNA translation by long-range base pairing is released by cytoplasmic splicing upon induction of the unfolded protein response. Cell 107: 103-114.

Sarkar, S. and Hopper, A.K. 1998. tRNA nuclear export in Saccharomyces cerevisiae: In situ hybridization analysis. Mol. Biol. Cell 9: 3041-3055.

Sarkar, S., Azad, A.K., and Hopper, A.K. 1999. Nuclear tRNA aminoacylation and its role in nuclear export of endogenous tRNAs in Saccharomyces cerevisiae. Proc. Natl. Acad. Sci. 96: $14366-14371$.

Schiffer, S., Rosch, S., and Marchfelder, A. 2002. Assigning a function to a conserved group of proteins: The tRNA 3'processing enzymes. EMBO J. 21: 2769-2777.

Schneider, A. and Marechal-Drouard, L. 2000. Mitochondrial tRNA import: Are there distinct mechanisms? Trends Cell Biol. 10: 509-513.

Sharma, K., Fabre, E., Tekotte, H., Hurt, E.C., and Tollervey, D. 1996. Yeast nucleoporin mutants are defective in pre-tRNA splicing. Mol. Cell. Biol. 16: 294-301.

Shen, W.C., Selvakumar, D., Stanford, D.R., and Hopper, A.K. 1993. The Saccharomyces cerevisiae LOS1 gene involved in pre-tRNA splicing encodes a nuclear protein that behaves as a component of the nuclear matrix. J. Biol. Chem. 268: 19436-19444.

Shi, P.Y., Maizels, N., and Weiner, A.M. 1998. CCA addition by tRNA nucleotidyltransferase: Polymerization without translocation? EMBO J. 17: 3197-3206.

Sidrauski, C. and Walter, P. 1997. The transmembrane kinase Ire $1 p$ is a site-specific endonuclease that initiates mRNA splicing in the unfolded protein response. Cell 90: 10311039.

Sidrauski, C., Cox, J.S., and Walter, P. 1996. tRNA ligase is required for regulated mRNA splicing in the unfolded protein response. Cell 87: 405-413.

Simos, G., Tekotte, H., Grosjean, H., Segref, A., Sharma, K., Tollervey, D., and Hurt, E.C. 1996. Nuclear pore proteins are involved in the biogenesis of functional tRNA. EMBO $J$. 15: $2270-2284$.

Smith, C.M. and Steitz, J.A. 1997. Sno storm in the nucleolus: New roles for myriad small RNPs. Cell 89: 799-809.

Spinelli, S.L., Consaul, S.A., and Phizicky, E.M. 1997. A conditional lethal yeast phosphotransferase (tpt1) mutant accumulates tRNAs with a 2 '-phosphate and an undermodified base at the splice junction. RNA 3: 1388-1400.

Spinelli, S.L., Malik, H.S., Consaul, S.A., and Phizicky, E. M. 1998. A functional homolog of a yeast tRNA splicing enzyme is conserved in higher eukaryotes and in Escherichia coli. Proc. Natl. Acad. Sci. 95: 14136-14141.

Sprinzl, M., Horn, C., Brown, M., Ioudovitch, A., and Steinberg, S. 1998. Compilation of tRNA sequences and sequences of tRNA genes. Nucleic Acids Res. 26: 148-153.

Srisawat, C., Houser-Scott, F., Bertrand, E., Xiao, S., Singer, R.H., and Engelke, D.R. 2002. An active precursor in assembly of yeast nuclear ribonuclease P. RNA 8: 1348-1360.

Steiger, M.A., Kierzek, R., Turner, D.H., and Phizicky, E.M. 2001. Substrate recognition by a yeast 2 '-phosphotransferase involved in tRNA splicing and by its Escherichia coli homo- log. Biochemistry 40: 14098-14105.

Szweykowska-Kulinska, Z., Senger, B., Keith, G., Fasiolo, F., and Grosjean, H. 1994. Intron-dependent formation of pseudouridines in the anticodon of Saccharomyces cerevisiae minor tRNA ${ }^{\text {Ile }}$. EMBO J. 13: 4636-4644.

Tan, T.H., Pach, R., Crausaz, A., Ivens, A., and Schneider, A. 2002. tRNAs in Trypanosoma brucei: Genomic organization, expression, and mitochondrial import. Mol. Cell. Biol. 22: 3707-3717.

Tavernarakis, N., Alexandraki, D., Liodis, P., Tzamarias, D., and Thireos, G. 1996. Gene overexpression reveals alternative mechanisms that induce GCN4 mRNA translation. Gene 179: 271-277.

Tolerico, L.H., Benko, A.L., Aris, J.P., Stanford, D.R., Martin, N.C., and Hopper, A.K. 1999. Saccharomyces cerevisiae Mod5p-II contains sequences antagonistic for nuclear and cytosolic locations. Genetics 151: 57-75.

Tomita, K. and Weiner, A.M. 2001. Collaboration between CCand A-adding enzymes to build and repair the 3'-terminal CCA of tRNA in Aquifex aeolicus. Science 294: 13341336.

Tomita, K., Ueda, T., and Watanabe, K. 1996. RNA editing in the acceptor stem of squid mitochondrial tRNA ${ }^{\text {Tyr }}$. Nucleic Acids Res. 24: 4987-4991.

Trotta, C.R., Miao, F., Arn, E.A., Stevens, S.W., Ho, C.K., Rauhut, R., and Abelson, J.N. 1997. The yeast tRNA splicing endonuclease: A tetrameric enzyme with two active site subunits homologous to the archaeal tRNA endonucleases. Cell 89: 849-858.

Urbonavicius, J., Qian, Q., Durand, J.M., Hagervall, T.G., and Björk, G.R. 2001. Improvement of reading frame maintenance is a common function for several tRNA modifications. EMBO T. 20: 4863-4873.

Warner, G.J., Berry, M.J., Moustafa, M.E., Carlson, B.A., Hatfield, D.L., and Faust, J.R. 2000. Inhibition of selenoprotein synthesis by selenocysteine tRNA ${ }^{[\mathrm{Ser}] \mathrm{Sec}}$ lacking isopentenyladenosine. J. Biol. Chem. 275: 28110-28119.

Wolin, S.L. and Cedervall, T. 2002. The La protein. Annu. Rev. Biochem. 71: 375-403.

Wolin, S.L. and Matera, A.G. 1999. The trials and travels of tRNA. Genes \& Dev. 13: 1-10.

Wu, P., Brockenbrough, J.S., Paddy, M.R., and Aris, J.P. 1998. NCL1, a novel gene for a non-essential nuclear protein in Saccharomyces cerevisiae. Gene 220: 109-117.

Xiao, S., Scott, F., Fierke, C.A., and Engelke, D.R. 2002. Eukaryotic ribonuclease P: A plurality of ribonucleoprotein enzymes. Annu. Rev. Biochem. 71: 165-189.

Xing, F., Martzen, M.R., and Phizicky, E.M. 2002. A conserved family of Saccharomyces cerevisiae synthases affects dihydrouridine modification of tRNA. RNA 8: 370-381.

Xu, F., Lin-Chao, S., and Cohen, S.N. 1993. The Escherichia coli pcnB gene promotes adenylylation of antisense RNAI of ColE1-type plasmids in vivo and degradation of RNA I decay intermediates. Proc. Natl. Acad. Sci. 90: 6756-6760.

Yermovsky-Kammerer, A.E. and Hajduk, S.L. 1999. In vitro import of a nuclearly encoded tRNA into the mitochondrion of Trypanosoma brucei. Mol. Cell. Biol. 19: 6253-6259.

Yokobori, S. and Paabo, S. 1995a. Transfer RNA editing in land snail mitochondria. Proc. Natl. Acad. Sci. 92: 10432-10435. 1995b. tRNA editing in metazoans. Nature 377: 490.

1997. Polyadenylation creates the discriminator nucleotide of chicken mitochondrial tRNA ${ }^{\text {Tyr }}$. J. Mol. Biol. 265: 9599.

Yoo, C.J. and Wolin, S.L. 1997. The yeast La protein is required for the 3 ' endonucleolytic cleavage that matures tRNA precursors. Cell 89: 393-402. 


\section{Hopper and Phizicky}

Yue, D., Weiner, A.M., and Maizels, N. 1998. The CCA-adding enzyme has a single active site. J. Biol. Chem. 273: 2969329700.

Yukawa, Y., Fan, H., Akama, K., Beier, H., Gross, H.J., and Sugiura, M. 2001. A tobacco nuclear extract supporting transcription, processing, splicing and modification of plant introncontaining tRNA precursors. Plant I. 28: 583-594.

Zillman, M., Gorovsky, M.A., and Phizicky, E.M. 1991. Conserved mechanism of tRNA splicing in eukaryotes. Mol. Cell. Biol. 11: 5410-5416.

. 1992. HeLa cells contain a 2 '-phosphate-specific phosphotransferase similar to a yeast enzyme implicated in tRNA splicing. J. Biol. Chem. 267: 10289-10294.

Zofallova, L., Guo, Y., and Gupta, R. 2000. Junction phosphate is derived from the precursor in the tRNA spliced by the archaeon Haloferax volcanii cell extract. RNA 6: 1019-1030. 


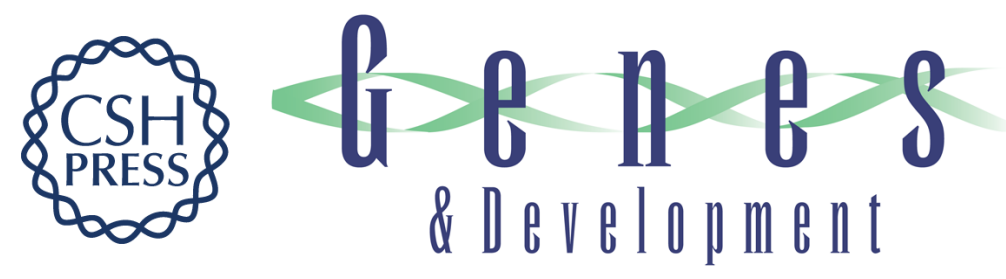

\section{tRNA transfers to the limelight}

Anita K. Hopper and Eric M. Phizicky

Genes Dev. 2003, 17:

Access the most recent version at doi:10.1101/gad.1049103

References This article cites 170 articles, 105 of which can be accessed free at: http://genesdev.cshlp.org/content/17/2/162.full.html\#ref-list-1

License

Email Alerting Receive free email alerts when new articles cite this article - sign up in the box at the top Service right corner of the article or click here.

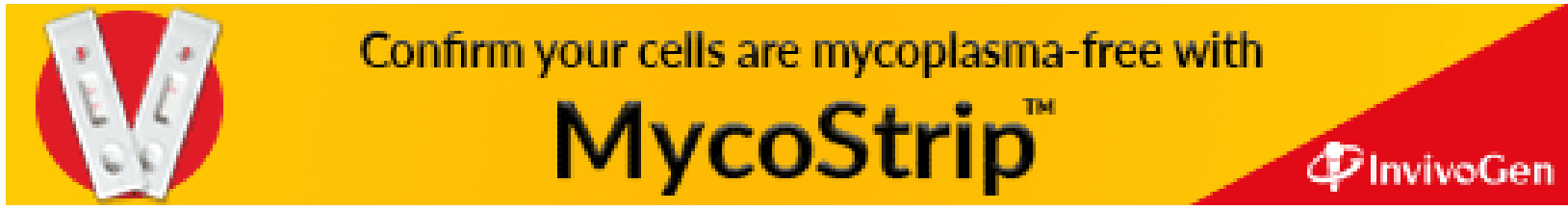

